\title{
Mesopause dynamics from the scandinavian triangle of radars within the PSMOS-DATAR Project
}

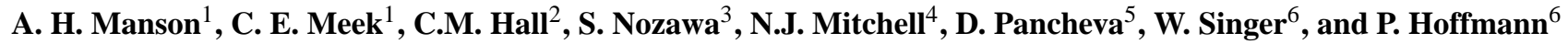 \\ ${ }^{1}$ Institute of Space and Atmospheric Studies, University of Saskatchewan, Canada \\ ${ }^{2}$ Troms $\varnothing$ Geophysical Observatory, University of Troms $\varnothing$, Norway \\ ${ }^{3}$ Solar-Terrestrial Environment Laboratory, University of Nagoya, Japan \\ ${ }^{4}$ Department of Electronic and Electrical Engineering, University of Bath, UK \\ ${ }^{5}$ Department of Physics, University of Wales, UK \\ ${ }^{6}$ Leibniz-Institute of Atmospheric Physics, Kühlungsborn, Germany
}

Received: 4 February 2003 - Revised: 2 July 2003 - Accepted: 22 July 2003 - Published: 1 January 2004

\begin{abstract}
The "Scandinavian Triangle" is a unique trio of radars within the DATAR Project (Dynamics and Temperatures from the Arctic MLT (60-97 km) region): Andenes MF radar $\left(69^{\circ} \mathrm{N}, 16^{\circ} \mathrm{E}\right)$; Troms $\varnothing \mathrm{MF}$ radar $\left(70^{\circ} \mathrm{N}, 19^{\circ} \mathrm{E}\right)$ and Esrange "Meteor" radar $\left(68^{\circ} \mathrm{N}, 21^{\circ} \mathrm{E}\right)$. The radar-spacings range from $125-270 \mathrm{~km}$, making it unique for studies of wind variability associated with small-scale waves, comparisons of large-scale waves measured over small spacings, and for comparisons of winds from different radar systems. As such it complements results from arrays having spacings of $25 \mathrm{~km}$ and $500 \mathrm{~km}$ that have been located near Saskatoon. Correlation analysis is used to demonstrate a speed bias (MF smaller than the Meteor) between the radar types, which varies with season and altitude. Annual climatologies for the year 2000 of mean winds, solar tides, planetary and gravity waves are presented, and show indications of significant spatial variability across the Triangle and of differences in wave characteristics from middle latitudes.
\end{abstract}

Key words. Meteorology and atmospheric dynamics (middle atmosphere dynamics; waves and tides: instrument and techniques)

\section{Introduction}

The spatial and temporal variability of the wind and wave fields of the Mesosphere and Lower Thermosphere (MLT; 60-110 km) remain one of the least well-studied and understood aspects of atmospheric dynamics. The MFR (Medium Frequency Radars) of the Canadian prairies have contributed significantly to our existing knowledge.

We provide a brief review of the relevant studies. The first involved GRAVNET, an MFR network designed to charac-

Correspondence to: A. H. Manson

(manson@dansas.usask.ca) terize Gravity Waves (GW) (Manson and Meek, 1988). It featured not one, but three spaced-antenna receiving arrays in a triangle of side about $40 \mathrm{~km}$. The winds obtained from each array were very similar, but their temporal variability and cross-spectral analysis provided unique GW characteristics (periods, 10- $300 \mathrm{~min}$; horizontal wavelengths, 40-1200 km).

This system was followed by the addition of two complete MFR systems to the main system at Saskatoon, forming a triangle of side near $500 \mathrm{~km}$. It became clear that the climatologies, for example, monthly profiles, of mean winds and tides were very similar and consistent; but that fluctuations in the daily values of all wave-types (tides, planetary and gravity waves), with time scales of 4 to 365 days, were highly correlated across the triangle at given altitudes $(60-88 \mathrm{~km})$ (Hall et al., 1995a). An unexpected result was that for the two GW bands (10-100 min, 2-6h) correlations between sites (500 km spacings) at a given height were higher than between neighbouring layers ( $15 \mathrm{~km}$ separation) at any site. Although some horizontal uniformity was expected, such altitude variability in GW propagation conditions was interesting and informative (for example, Zhong et al., 1996). Coupling between wave-types was noted. A companion paper (Hall et al., 1995b) focussed on inertial GW (2-10 hour period) and was consistent with the first study in that temporal hodographs at specific heights were much more regular or coherent than were oscillations over a $20 \mathrm{~km}$ height interval at a particular time. It was also frequently the case that although an oscillation due to an inertial GW could be identified at each $(500 \mathrm{~km})$ site, the frequency characteristics of those oscillations were often different, indicating dispersion of the wave and wave-packet over $500 \mathrm{~km}$. This made crossspectral analysis methods of determining the GW characteristics challenging or impossible. Nevertheless, useful GW characteristics and climatologies were determined.

The development of observing systems in Northern Scandinavia and the Arctic has serendipitously provided a triangle 


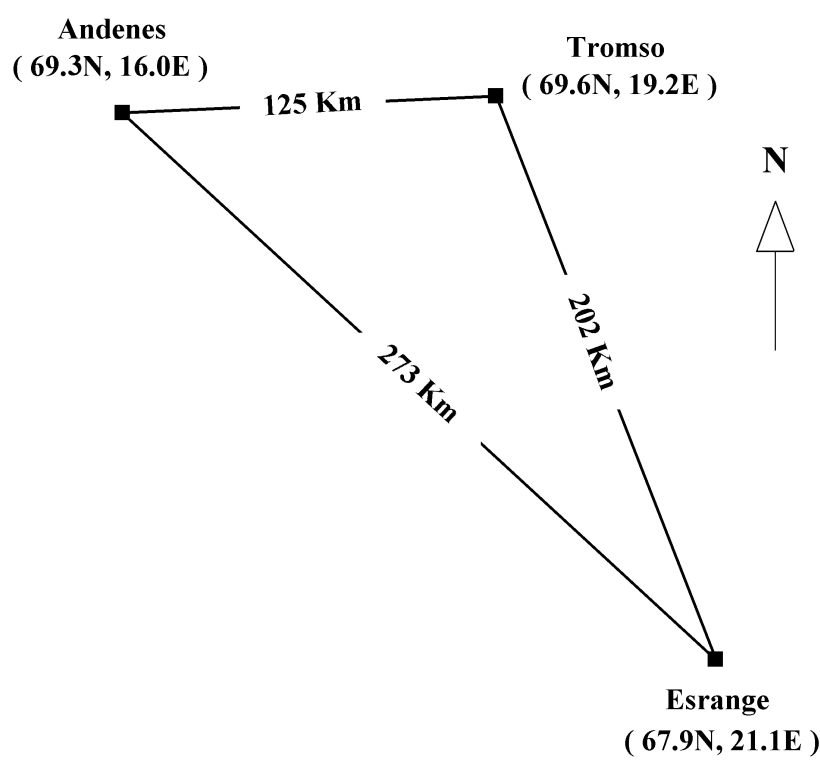

Fig. 1. Map of the three MLT radar locations.

of MLT radars, which is $\sim 50 \%$ of the size of the $500 \mathrm{~km}$ Canadian Prairies' array: the Scandinavian-Triangle or STriangle. There is a "Meteor Wind Radar" (MWR) at Esrange, and MFRs at Troms $\varnothing$ (co-located with EISCAT) and Andenes (co-located with ALOMAR), which are described in Sect. 2. The dimensions and positions for this "Scandinavian Triangle" are shown in Fig. 1. Topics of interest to the community have changed since the studies discussed above, so we shall not simply repeat those, although some themes will re-appear here. A topic of great interest, encouraged by SCOSTEP's PSMOS (Planetary Scale Mesopause Observing System, 1998-2002) Programme, is the spatial variability of local oscillations in the wind-field, i.e. 12-, 24-h periodicities that are manifestations of the tide, and 2-, 16-d periodicities that are manifestations of Planetary Waves (PW). Both of these wave-types are global phenomena, since they are theoretically described by Hough modes, but smaller scale structures co-exist with them. Examples include non-(solar) migrating tidal modes, which are clearly seen in recent analysis of HRDI (High Resolution Doppler Interferometer) satellite data (Manson et al., 2002a).

We have also recently completed studies of winds and wave-types (tides, planetary waves (PW), and GW) for a network of middle-latitude MFRs called CUJO: Canada U.S. Japan Opportunity. The locations are London $\left(43^{\circ} \mathrm{N}\right.$, $\left.81^{\circ} \mathrm{W}\right)$, Platteville $\left(40^{\circ} \mathrm{N}, 105^{\circ} \mathrm{W}\right)$, Saskatoon $\left(52^{\circ} \mathrm{N}\right.$, $\left.107^{\circ} \mathrm{W}\right)$, Wakkanai $\left(45^{\circ} \mathrm{N}, 141^{\circ} \mathrm{E}\right)$, Yamagawa $\left(31^{\circ} \mathrm{N}\right.$, $131^{\circ} \mathrm{E}$ ), and offer separations of $1000-7000 \mathrm{~km}$ in longitude and 12 degrees (circa $1200 \mathrm{~km}$ ) in latitude. As with the HRDI-tidal study mentioned above, longitudinal variations in tidal characteristics (and PW) were very significant, often being larger than over 12 degrees of latitude (at a common longitude). The analysis used in these two papers (Manson et al., 2003a, 2004a will be repeated here, as will references to similarities in spatial effects.
Here we compare winds across the triangle in a correlation technique that provides a unique height calibration and speed-ratio assessments between radar types (Sect. 4). Annual climatologies of mean winds, tides, and PW are shown in Sections 3, 5, and 6. Also, in Sect. 7, the temporal variabilities of GW variances ( $2-6 \mathrm{~h}$ periods) are compared across the Triangle. The opportunity to compare wind observations from different MLT radar types is valuable and receives appropriate discussion (Sections 4 and 8).

\section{Radars and Data Analysis}

\subsection{Radars}

The Troms $\emptyset$ MF radar $(2.78 \mathrm{MHz})$ is located at the EISCAT site of Ramfjordmoen $\left(70^{\circ} \mathrm{N}, 19^{\circ} \mathrm{E}\right)$ and has been described in the recent papers already referenced, and in particular by Hall (2001). The spaced antenna "full correlation analysis" (FCA) method is used (Meek, 1980). Vertical soundings provide wind sampling at 3-km intervals every $5 \mathrm{~min}$ from near 60 to $120 \mathrm{~km}$. The Andenes MFR (1.98 MHz), which is located at the ALOMAR site $\left(69^{\circ} \mathrm{N}, 16^{\circ} \mathrm{E}\right)$, is effectively of the same design (including electronics and antenna system), although the winds are available at $2 \mathrm{~km}$ and 2 min intervals. It uses the more classical method of analysis due to Briggs (1984). Comparisons have shown that no significant differences exist between these methods (Thayaparan et al., 1995). It is important to note that despite design similarities in the antennas there could be operational differences between the Troms $\varnothing$ and Andenes systems: factors include the groundplane, and coupling with neighbouring antenna systems (this latter could be more significant for the Troms $\varnothing$ MFR). For the analyses described in Sect. 2.2 the basic data product is usually the hourly mean, but to be consistent with the meteor radar a 2-h mean formed every hour is also used.

The new University of Bath meteor radar (MWR) is located at Esrange $\left(68^{\circ} \mathrm{N}, 21^{\circ} \mathrm{E}\right)$, which is the Swedish Space Corporation's rocket range near Kiruna in Northern Sweden. The radar uses a transmitter of $6 \mathrm{~kW}$ peak power, and operates at a frequency of $32.5 \mathrm{MHz}$. Crossed-element Yagi antennas are used for both transmitting and receiving. A single antenna acts as the transmitter and five separate antennas are used as receivers. The radar operates in an "all-sky" configuration, with radiated power being largely independent of azimuth. The five individual receiver antennas form an interferometer to determine meteor echo azimuth and elevation angles. The elevation angle measurements, in combination with measurements of the echo range, allow for meteor-echo heights to be estimated, with a height resolution of typically $<2 \mathrm{~km}$. The MLT circle from which meteors are detected is of diameter $500 \mathrm{~km}$, with a median (horizontal) range of circa $130 \mathrm{~km}$; there is a rather uniform azimuthal distribution of detected meteors; and the diurnal variation of detected meteors, while peaking near 05:00 UT, is modest and not thought to affect the analysis of tides during the year (Mitchell et al., 2002). (In comparison, the MLT circle from which MFR 
echoes are acquired is of diameter near $60 \mathrm{~km}$ (Meek et al., 1986).) Continuous data collection commenced on $5 \mathrm{Au}-$ gust 1999. A detailed description of the various steps in the data processing techniques used to discriminate between echoes from meteors and all other signals is give by Hocking et al. (2001). In this paper the data have been assigned to the nearest $3 \mathrm{~km}$ height interval, as used by the MFR at Troms $\varnothing$, for convenience in forming contour plots throughout the MLT region (see Sect. 2.2 below). The basic data products are 2-h means that are formed every hour.

Since all wind measurement systems potentially have biases or selectivity issues, some comment about the accuracy of the radar-winds is appropriate. Examples of system comparisons include an MFR and Meteor Wind Radar (MWR) at $43^{\circ} \mathrm{N}$ (Hocking and Thayaparan, 1997); MFRs and Fabry-Perot Interferometers ("green line" and hydroxyl) at two $52^{\circ} \mathrm{N}$ locations (Manson et al., 1996; Meek et al., 1997); and rockets and radars (MFR, VHF and EISCAT) near $70^{\circ} \mathrm{N}$ (Manson et al., 1992). In all of these studies the phases of the tides, or directions of the winds, have generally been satisfactorily consistent, for example, means within standard errors, as assessed by the authors. The Saskatoon optical-MFR comparisons showed no speed biases, but "SKiYMET" MWR-MFR speed-comparisons at Saskatoon during the summer of 1998 have shown modest differences, for example, MWR/MFR ratios of about 1.33 (Meek, Hocking and Manson, Private Communication, 2002) at $88 \mathrm{~km}$ altitude; and for similar altitudes at $70^{\circ} \mathrm{N}$, Troms $\varnothing$, the speeds from the MFR were smaller by a factor of 1.54 than those from other systems. For our purposes here, we will bear in mind the potential biases between different experiments when any later comparisons are made in this paper. There will also be an opportunity to specifically compare the MWR and MFR speeds across the Triangle.

\subsection{Analysis techniques}

To provide an annual climatology of atmospheric oscillations from 5-h to 30-d at a chosen height a wavelet analysis is applied to a year of hourly mean winds with additional data at the ends, if available, to cover the full sliding window for all wave periods used (Fig. 2). A Gaussian window of length 6 times the period (truncated at 0.05 of peak value) is used to approximate a Morlet wavelet analysis (Kumar and Foufoula-Georgiou, 1997), but one in which gaps do not have to be filled. Criteria for the existence of data are described later. A Fourier transform (not an FFT) is therefore used and applied to existing data points only. Each time-axis pixel (800 are used) represents several hours, since the axis covers 1 year. Breaks in the heavy data-existence line at the bottom of the frame indicates that there were no data for those hours, and are a warning that spectral data near the edges of, and during, these intervals may be inaccurate. The periodscale uses 600 pixels and is linear in log (period) from 5 to $730 \mathrm{~h}$. Each pixel represents one spectral value, and there is no smoothing.
Amplitudes are corrected after calculations for attenuation by the window, but on the assumption that there were no significant gaps. In the plot the value in $\mathrm{dB}$ is equal to $20 \log 10$ (wave amplitude in $\mathrm{m} / \mathrm{s}$ ). Data in such plots are usually scaled according to the maximum wave amplitude for each figure, but for this paper, for ease of intercomparison of sites/components, a limit of $30 \mathrm{~dB}$ is used for all of the MFR sites. For Esrange, a limit of $33 \mathrm{~dB}$ is used to enhance the comparisons of wave-types as seen across the $\mathrm{S}$-Triangle. The few larger values, up to the maximum of $35 \mathrm{~dB}$, were placed in the colour segment $31.5-33.0 \mathrm{~dB}$.

The monthly tidal analysis uses a least-squares fit of a mean, 24-h and 12-h tidal oscillations to a composite monthly day in which the squared error is weighted by the number of raw $(5 \mathrm{~min})$ values in each composite hour. As in the tidal papers referenced earlier there must be data in at least 16 of the possible 24-composite hours. The mean winds (Fig. 4) and tidal contours (Figs. 5 and 7) cover 6 heights and 12 months. There is no smoothing. Interpolation between data points employs a "bilinear patch" method (BLP), viz. the interpolated value is $a x+b y+c x y+d$, where $a, d, c, d$ are solved from the corner values of a cell. In the case of phase contours, two separate BLP calculations are done, one for cosine and one for sine, and combined to obtain the interpolated phase value. If the phases at corners of the cell have a spread greater than 180 degrees, then no interpolation is attempted, since the possibility of multiple solutions cannot be ignored, and the cell is left unfilled. Any pixels representing a value greater than the maximum in the legend are set equal to the maximum. (It should be noted that the weighting used by hour for the least-squares fitting was not important, as unweighted fitting for both MFR and MWR data produced contours that were effectively unchanged.) Finally, MFR data, for which the heights are expected to be inaccurate, due to virtual versus real height considerations (Namboothiri et al., 1993), are not used. This leaves gaps at the greatest heights in summer. Five heights of the Global Scale Wave Model (GSWM 2000) have been plotted (Fig. 6) on the same scale to provide comparisons with the observations.

An independent Planetary Wave (PW) analysis is done for selected frequencies, starting with a year of hourly mean data which is extended at the ends, if data are available, to accommodate the desired window length. For the 16-d period, a 48-d window length, and for 2-d periods, a 24-d window, are each shifted in 5-d day steps over the year (Figures 8,9). For each of these window-lengths the mean is removed and used to represent the background wind, a full cosine window (Hanning) is applied, and the Fourier transform is done at the single selected PW frequency. Gaps are not filled.

The following data rejection criteria apply to both this analysis and to the earlier wavelet analysis. The spectral values are accepted, if at least $80 \%$ of the phases for that wave are available from the windowed data in each of two separate period intervals within the window, i.e. data must be available in $80 \%$ of the 'phase-bins' in at least two separate cycles. Otherwise, the pixel is left white (data omitted). To facilitate the application of this criterion the phases are subdi- 
vided into 24 bins; but in the case of the wavelet analysis for periods less than $24 \mathrm{~h}$ the number of bins is equal to the period in hours. Note that this criterion is similar to our weaker criterion for tidal fits (above), in which we require data in 16 different UT hours for tidal analysis, but where we fit 5 components simultaneously.

The presentation of GW data (Fig. 10) follows a methodology and format similar to that in our earlier papers (for example, Manson et al., 1999a). A difference filter, particularly valuable when there are gaps in time sequences, has been applied to the data. It is applied to hourly mean data (Gavrilov et al., 1995), and is equivalent to a band-pass filter of approximately $2-6 \mathrm{~h}$. The r.m.s. outputs from these filters may be described in terms of horizontal wind-perturbation ellipses, or more properly, "ovals" (hereafter "perturbation ovals"). On a time scale of one month, these are used to demonstrate variations in GW variances (from the relative magnitudes of the major axes) and predominant GW propagation directions (from the major axes, with directions uncertain by 180 degrees).

The differences in the ways in which the data are accumulated within the three radar systems require that adjustments be made to the outputs from this difference filter. Based on the assumption that the variance of an hourly mean is inversely proportional to the amount of data averaged, we use the data numbers in each hour to normalize each Troms $\varnothing$ and Andenes squared hourly difference. This provides an estimate of what would have been obtained with "full" hours of data. The Esrange data, assumed to be comprised of "full" hours already, are 2-hourly means shifted by $1 \mathrm{~h}$; so they are adjusted accordingly to match the MF values. In addition, since the effective time difference between adjacent hourly values is greater than $1 \mathrm{~h}$, a factor of 0.315 (quoted on the plot) is applied (this assumes the horizontal wind has a spectral slope, $\log \log$ of $5 / 3$ ). The height layers for the MFRMWR comparison are different from the MFR-MFR comparison because of the more limited range of meteor data.

Significance levels were calculated (Gavrilov et al., 1995) as to whether the degree of ellipticity or departure from circularity was meaningful, given the number of points or values used for the calculation of the ovals. Generally, the numbers of values in a month for the height layers used are so large (several thousand), that all ovals showing visible elongations have significance of orientation/ellipticity of at least $95 \%$ and usually $99 \%$.

\section{Climatologies of Oscillations (5-h to 30-d)}

The annual contours of wavelet intensities as functions of frequency versus time, for the altitude of $85 \mathrm{~km}$, and at the three locations in Scandanavia and for Saskatoon $\left(52^{\circ} \mathrm{N}\right.$, $107^{\circ} \mathrm{W}$ ) are shown in Fig. 2. We have included the midlatitude location to illustrate the characteristic changes in atmospheric waves over circa 20 degrees of latitude. The altitude was chosen as a compromise, since at this mesopause height the tides and planetary waves (16-, 2-day) are all normally present with significant amplitudes. Brief mention of the PWs is made here, but specific discussion and figures follow in Sect. 6.

The spectra for the three $70^{\circ}$ N MLT radars are quite similar in characteristics. For the 12-h tide and in both wind components (meridional, NS and zonal, EW) there are maxima in the late-summer/autumn, somewhat lesser ones in winter, and perhaps increases in the spring; at Esrange the minima during October are particularly short in duration and will be clearer in the contour plots for the MLT which follow in Sect. 5. For the 24-h tide there are generally maxima in summer-centered months (typically March to September). There are some monthly differences already evident between Esrange and Andenes-Troms $\emptyset$, which will also be well defined in the later multi-height contour plots, for example, the EW component at Esrange has relatively weak amplitudes in the later summer-autumn months at this altitude of $85 \mathrm{~km}$. It should be noted that the Esrange contours have been moved by $3 \mathrm{~dB}$, which is consistent with the earlier system comparisons (Andenes-systems/Troms $\varnothing$-MFR) which showed a speed ratio of $\sim 1.5$. This possible bias will be discussed later in more detail. The $52^{\circ} \mathrm{N}$ tidal spectra are quite similar to those at $70^{\circ} \mathrm{N}$, although the 12-h tide's winter and spring maxima are clearer, and the 24-h tide's maximum is reached in spring rather than summer.

The PW features of Fig. 2 are also similar at the three $70^{\circ} \mathrm{N}$ MLT radars; for example, with the quasi-2-d wave having bursts of activity in summer and also in the winter months (see also Nozawa et al., 2003). Both components are involved. At Saskatoon the more familiar pattern of dominant activity during the summer at mesopause heights is revealed for this so-called "Rossby-gravity normal mode". The other PWs, which have received most attention at middle latitudes, are the Rossby (normal) modes (the so-called 5, 10, 16-d waves). The ranges of observed periods associated with these are typically $5-7,8-10,12-22$ days due to Doppler shifting by the background winds (Luo et al; 2002a, b). Indeed, in this year at $52^{\circ} \mathrm{N}$ there are maxima in winter months for the 16-d PW in the EW component, and more intermittent activity (occurrences of contours above $22.5 \mathrm{~dB}$ ) between the $2-\mathrm{d}$ and 16- $\mathrm{d}$ band. The $70^{\circ} \mathrm{N}$ MLT radars have a similar pattern, but the 16- $\mathrm{d}$ EW amplitudes appear slightly weaker (Luo et al., 2002b), and the activity in the NS component is relatively more substantial, as will become clearer later when specific 16-d contour plots are discussed. There are also contours above the $22.5 \mathrm{~dB}$ level for periods of 20-30 days which have been described as "extra long period" oscillations by Luo et al. (2001). These were shown to have correlations with the solar rotation period, and to have climatologies rather similar to those of the 16-d PW. Generally speaking, the occurrences of substantial activity (contours above $22.5 \mathrm{~dB}$, yellow to red) in the band from 2 to 30 days are quite similar at the three MLT radars for example, close to 16 days in January (NS); 5-10 days in December (EW), and 2 days in July (NS). However, even over scales of 125-270 km in Figure 2, the spatial-temporal intermittency noted in the North AmericaPacific sector (Luo et al., 2002a, b) and in the CUJO network (Manson et al., 2003b) is evident here. 


\section{$85 \mathrm{Km}$}

NS
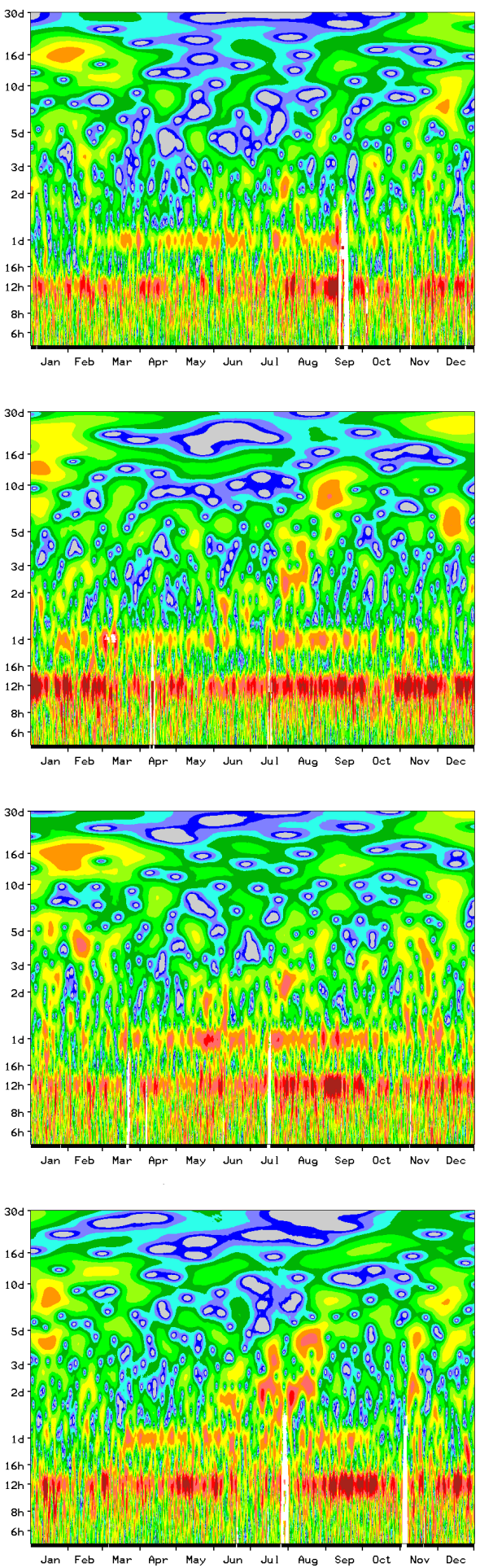

EW
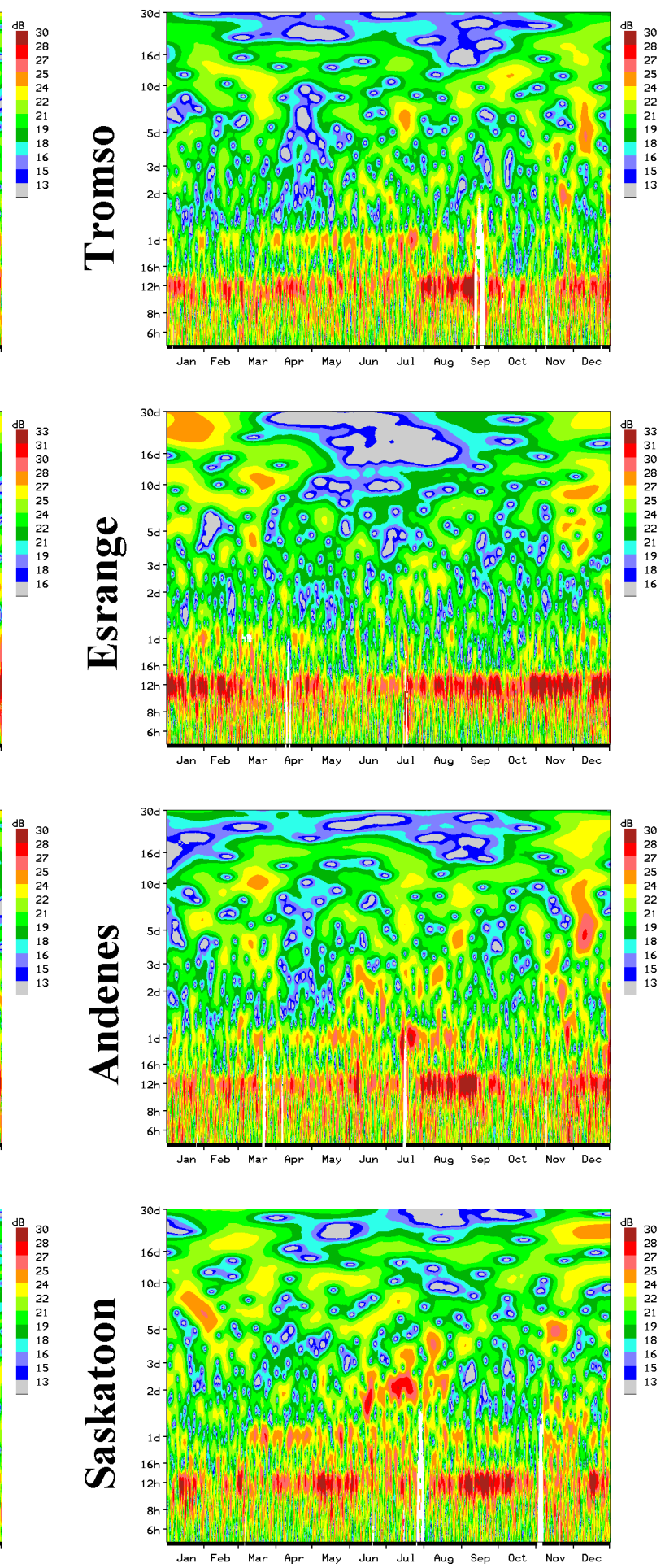

Fig. 2. Annual (2000) contours of wavelet intensities as functions of frequency versus time for the meridional and zonal (NS, EW) components of the winds at four locations (Saskatoon, and the 3 Scandinavian-Triangle sites, Troms $\varnothing$, Esrange, Andenes); the altitude is $85 \mathrm{~km}$. Analysis details are provided in Sect. 2. A dB limit of 33 is used for the MWR at Esrange and 30 for the MFRs, to account for the speed-bias found earlier (Manson et al., 1992) and to allow for easier comparison of the spectral features. 
Table 1. Ratios of variances of the winds from the three MLT radars: E, Esrange; A, Andenes; T, Troms $\varnothing$. The values are calculated for the height of best correlation between the two respective data sets.

\begin{tabular}{|c|c|c|c|c|c|c|c|c|c|c|c|c|}
\hline $\mathrm{E}_{\mathrm{km}}$ & \multicolumn{12}{|c|}{$\left(\sigma_{E} / \sigma_{T}\right) \times 100$} \\
\hline 97 & 176 & 148 & 141 & 148 & 146 & 139 & 148 & 172 & 142 & 160 & 180 & 164 \\
\hline 94 & 183 & 161 & 138 & 140 & 132 & 120 & 122 & 151 & 133 & 167 & 155 & 151 \\
\hline 91 & 155 & 149 & 134 & 130 & 117 & 108 & 108 & 125 & 125 & 142 & 149 & 143 \\
\hline 88 & 142 & 135 & 119 & 117 & 108 & 111 & 105 & 110 & 115 & 119 & 134 & 141 \\
\hline 85 & 129 & 131 & 111 & 111 & 107 & 111 & 106 & 111 & 103 & 107 & 115 & 130 \\
\hline 82 & 117 & 112 & 112 & 100 & 112 & 119 & 104 & 112 & 95 & 97 & 106 & 108 \\
\hline $\mathrm{E}_{\mathrm{Km}}$ & \multicolumn{12}{|c|}{$\left(\sigma_{E} / \sigma_{A}\right) \times 100$} \\
\hline 97 & 231 & 188 & 172 & 147 & 118 & 123 & 126 & 145 & 141 & 195 & 190 & 171 \\
\hline 94 & 218 & 166 & 162 & 151 & 108 & 105 & 110 & 129 & 130 & 173 & 166 & 158 \\
\hline 91 & 186 & 160 & 144 & 138 & 104 & 102 & 97 & 108 & 121 & 147 & 156 & 143 \\
\hline 88 & 161 & 141 & 127 & 125 & 100 & 106 & 101 & 105 & 114 & 131 & 135 & 140 \\
\hline 85 & 137 & 133 & 112 & 123 & 105 & 109 & 201 & 108 & 105 & 116 & 114 & 127 \\
\hline 82 & 121 & 116 & 107 & 119 & 113 & 134 & 199 & 122 & 102 & 107 & 107 & 105 \\
\hline $\mathrm{T}_{\mathrm{Km}}$ & \multicolumn{12}{|c|}{$\left(\sigma_{T} / \sigma_{A}\right) \times 100$} \\
\hline 97 & 126 & 114 & 115 & 100 & 82 & 91 & 86 & 102 & 92 & 125 & 108 & 108 \\
\hline 94 & 119 & 112 & 110 & 112 & 81 & 86 & 85 & 88 & 99 & 119 & 108 & 105 \\
\hline 91 & 112 & 114 & 109 & 107 & 90 & 89 & 92 & 87 & 93 & 104 & 98 & 94 \\
\hline 88 & 113 & 111 & 105 & 107 & 92 & 92 & 98 & 93 & 100 & 108 & 98 & 94 \\
\hline 85 & 108 & 105 & 102 & 109 & 91 & 108 & 107 & 96 & 102 & 107 & 96 & 95 \\
\hline 82 & 105 & 104 & 98 & 112 & 101 & 111 & 113 & 108 & 107 & 110 & 103 & 94 \\
\hline & $\mathbf{J}$ & F & $\mathrm{M}$ & A & $\mathrm{M}$ & $\mathrm{J}$ & $\mathrm{J}$ & A & $S$ & $\mathrm{O}$ & $\mathrm{N}$ & $\mathrm{D}$ \\
\hline
\end{tabular}

\section{Correlations of the Wind Field Across the Triangle: Height Calibrations and Speed Ratios}

For comparisons of the contours (height versus time) of the mean wind and various wave types (tides, GW and PW) across the S-Triangle a good height calibration for each radar is highly desirable; at each system great care has been taken to optimize this process. Electronic calibrations have been used, but the use of targets at known altitudes, for example, balloons, which are the most desirable, are not yet available. Errors of $2 \mathrm{~km}$ are still possible between systems, as problems involving uncertainties in the ground-plane for antennas can introduce errors of this magnitude.

It seems useful, however, to use the data in rather raw form, before harmonic analysis is applied to investigate the wave types and to assess the existing height calibrations. We repeat and extend analysis developed for the Canadian triangular array of 3 MFRs. The simplest but highly effective approach was to form composite or mean-days of wind vectors $(\sim 80-100 \mathrm{~km})$ from hourly-mean values, over intervals of typically one month (for example, Manson and Meek, 1991a). Such plots are dominated by the tides, especially in the winter and autumn months, and show regular vector rotations with time at particular heights, and with heights $(3 \mathrm{~km}$ intervals) at particular times. For the Canadian-Triangle such plots were extremely similar at the $500-\mathrm{km}$ spacings, and "pattern recognition" showed the highest correlations of time sequences to be at identical gated-heights, i.e. the height calibrations were correct to better than $3 \mathrm{~km}$, assuming no tilt of the atmosphere or of dynamic processes.

Composite days were formed for the MLT radars of the S-Triangle during a winter month (January), when the 12-h tide provided clear temporal rotation of the vectors and also phase-progression with height. (The 2-hour means available were spaced by $1 \mathrm{~h}$.) Instantaneous or common UT, values were used. The wind and wave patterns were very similar, but from careful inspection, differences in heights for the highest correlations (similarity) of vector time sequences emerged. Winds for a height gate $\mathrm{h}(\mathrm{km})$ at Esrange were most similar to those at (h or h-3) at Tromsø and at (h or $\mathrm{h}+2)$ at Andenes.

A quantitative analysis was developed for the wind vector comparisons, which provided correlations between the twelve monthly time-sequences of 2-hour means for any radar-pair, and for all heights (circa $80-100 \mathrm{~km}$ ). The method involves complex (i.e.wind vector) cross correlations, and selection of the height-pair with maximum correlation. These results confirmed the method of visual inspection and provided a full year of analysis. Taking the median differences, as there were no trends with height or month, values at height gate (h) at Esrange were most highly correlated with (h-1.5) at Troms $\varnothing$ and $(\mathrm{h}+2)$ at Andenes. These are small factors and consistent with possible real uncertainties in absolute height calibrations.

There is, however, a final consideration, when comparing winds for a fixed UT from radars separated by 3 and $2^{\circ}$ in 


\section{Esrange (MWR) vs. Tromso (MF): $88 \mathrm{Km} 2 \mathrm{hr}$ mean winds}

\section{0: Jan, Feb, Dec}

NS

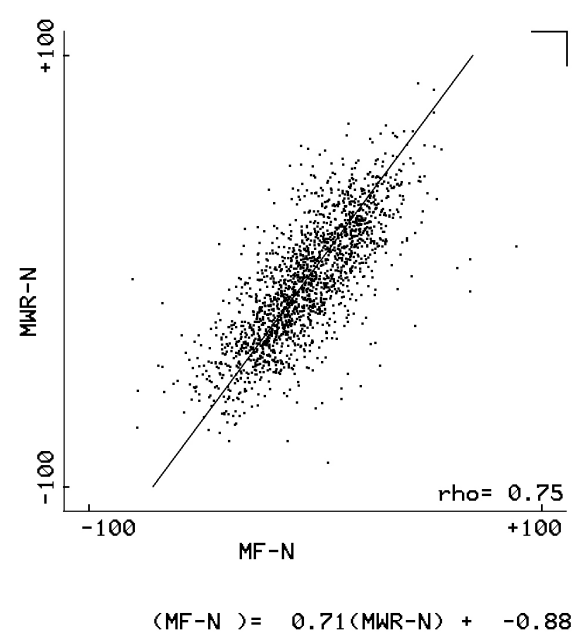

EW

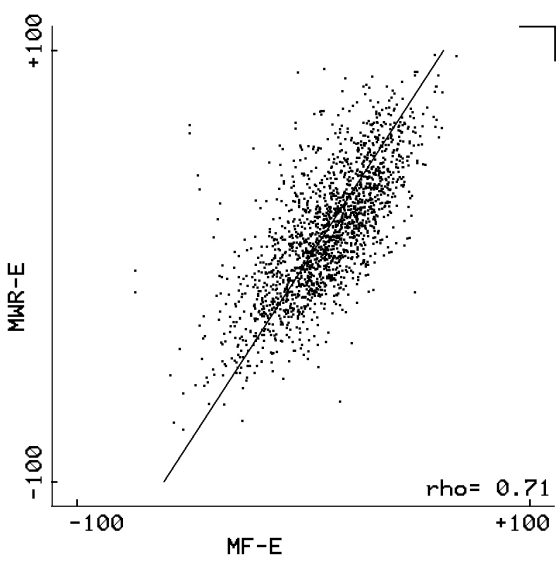

$(M F-E)=0.62(M W R-E)+0.39$

2000: Jul, Aug

NS

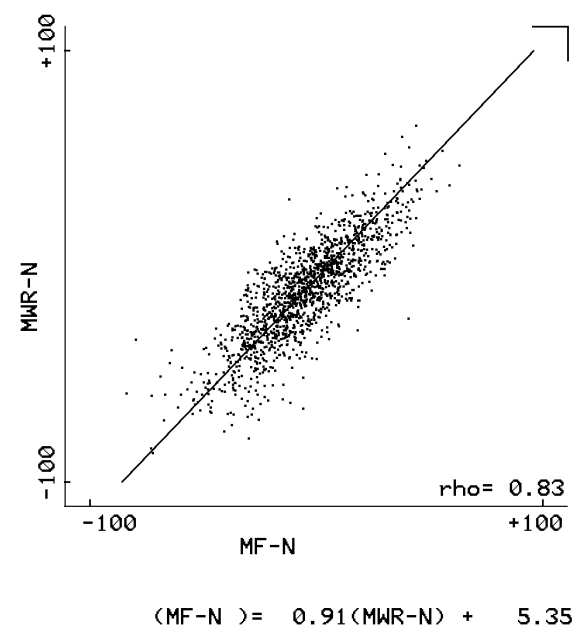

EW

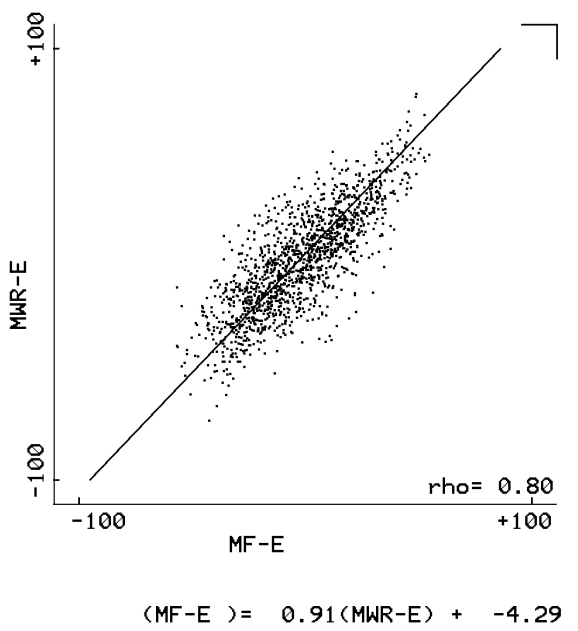

Fig. 3. Plots of wind-components (EW, zonal and NS, meridional) for the Meteor Winds Radar (MWR, Esrange) versus the Medium Frequency Radar (MF, Troms $\varnothing$ ): the height of $88 \mathrm{~km}$ is shown for the winter (January, February and December) and summer (June, July and August). The lines of best fit (least-squares) are shown, as are the equations (with slope and offset) of these lines. Correlations (rho) are also provided.

longitude (Fig. 1). There will be a phase (angle) difference for the vectors, depending upon the migrating tide. Because of this factor, and the vector-angle changes with height due to the dominant tide, both the composite day and correlation, analyses will show a small offset in heights of maximum correlation even when the radars are perfectly calibrated: the relation is approximately $(\mathrm{h})$ Esrange $=(\mathrm{h}+1)$ Troms $\emptyset=$ $(h+2)$ Andenes. When compared with the relation for height differences using the correlation method, this shows that the height calibrations for Esrange and Andenes are probably correct, and that the Troms $\varnothing$ values of $\mathrm{h}$ should be increased by circa $3 \mathrm{~km}$.

With this result available, subsequent analyses can proceed in two ways. Harmonic and spectral analysis can be applied and contour plots formed (Sect. 2) using gated heights for Troms $\varnothing$, modified or corrected by the modest but still significant factor just determined. At first thought this should produce greater similarity of climatological features (in height) than without such intervention. Indeed, it is the case that mean-wind and tidal contours formed without "correction" 

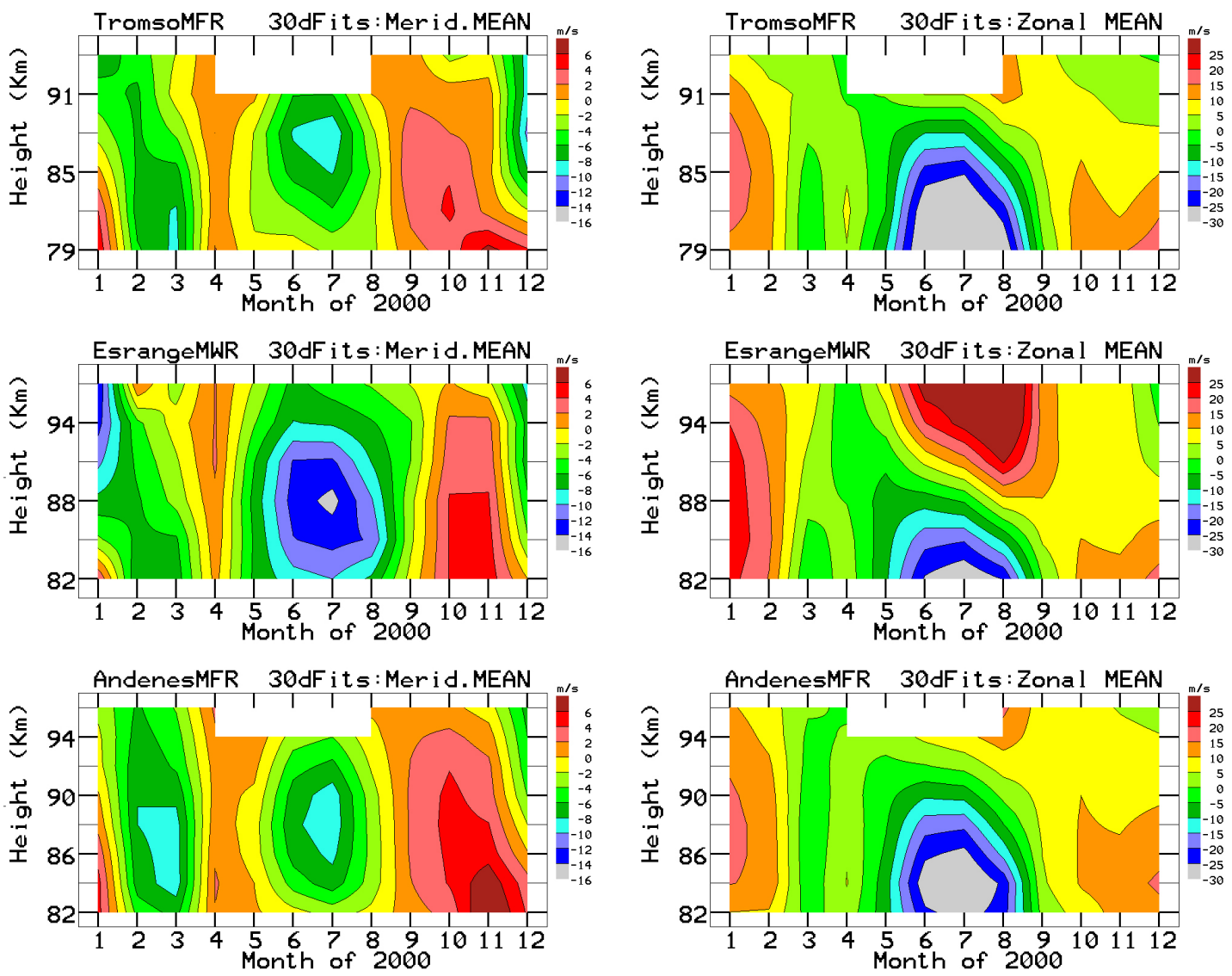

Fig. 4. Annual (2000) contours of the EW (zonal) and NS (meridional) components of the mean winds, as functions of height versus time: plots for Troms $\emptyset$, Esrange and Andenes are shown. Data from Troms $\emptyset$ are shown for a height-range lower by $3 \mathrm{~km}$ to enhance the similarities of contours/colours. This is consistent with the height calibration discussion of Sect. 2.

(below in Sect. 5) do show small altitudinal differences consistent with those factors just determined. On the other hand, the method used does not prove that the height calibration for the Troms $\emptyset$ MFR is in error by $3 \mathrm{~km}$. There could be complex dynamical processes, local to each MLT radar, which produce this difference. And since this paper is focussed on a comparison of the winds from three radars at spaced locations we argue to retain the experimentally calculated height calibrations.

However, we show an extra $3 \mathrm{~km}$ of data for Troms $\varnothing$ that will be found to provide better visual agreement of contours and "colours", and perhaps a persuasive argument that such a correction is appropriate. It is also consistent with the more limited radar height comparisons carried out during the PMSE observations of 1994 (Bremer et al., 1996).

While dealing with the 2-hour means (at common UT) there was the opportunity to compare the wind components from the two radar types. In Fig. 3 we show such plots for Esrange (MWR) and Troms $\emptyset$ (MFR) during the winter (January, February, December, 2000) and summer (July, August) months at $88 \mathrm{~km}$. Plots for both wind components are shown. Based upon the slopes of these lines for the summer, and the histograms of vector-angle differences that were also produced (not shown), best agreement between the data sets occurred when there was no height difference between the systems ( $3 \mathrm{~km}$ were assessed also). This is consistent with the vector-correlation method, where only a $1.5-\mathrm{km}$ offset $((\mathrm{h})$ Esrange $=(\mathrm{h}-1.5)$ Troms $\emptyset)$ was found. For the winter, when the tidal oscillations are stronger (Sect. 5), the histograms indicated best agreement for an interpolated $1-\mathrm{km}$ difference in the gated heights. The data are close to the lines of best-fit, indicating good quality data with high correlations (the correlation coefficients are also on the figure).

The slopes of the lines of best-fit differ between seasons: MWR/MFR is 1.41-1.61 in winter, and 1.1 in summer. This is the first time that seasonal differences have been reported, and we have no explanation for this. The calculation was repeated for 2001, and ratios of 1.33-1.39 and 1.19-1.14 respectively, were obtained. The ratios are similar to those found earlier (Manson et al., 1992) for the Andenes systems compared with the Tromsø MFR (1.54).

The correlation analysis used for the height comparisons were also used to show the height and monthly variation in the speed differences. The total variances (NS, EW) have been formed and ratios calculated for the Troms $\varnothing$-Andenes MFR pair $(\sigma T / \sigma A)$, the Esrange (MWR)-Andenes (MFR) pair $(\sigma E / \sigma A)$, and the Esrange-Troms $\emptyset$ pair $(\sigma E / \sigma T)(\mathrm{Ta}-$ ble 1$)$. The variances will be dominated by tidal winds. 

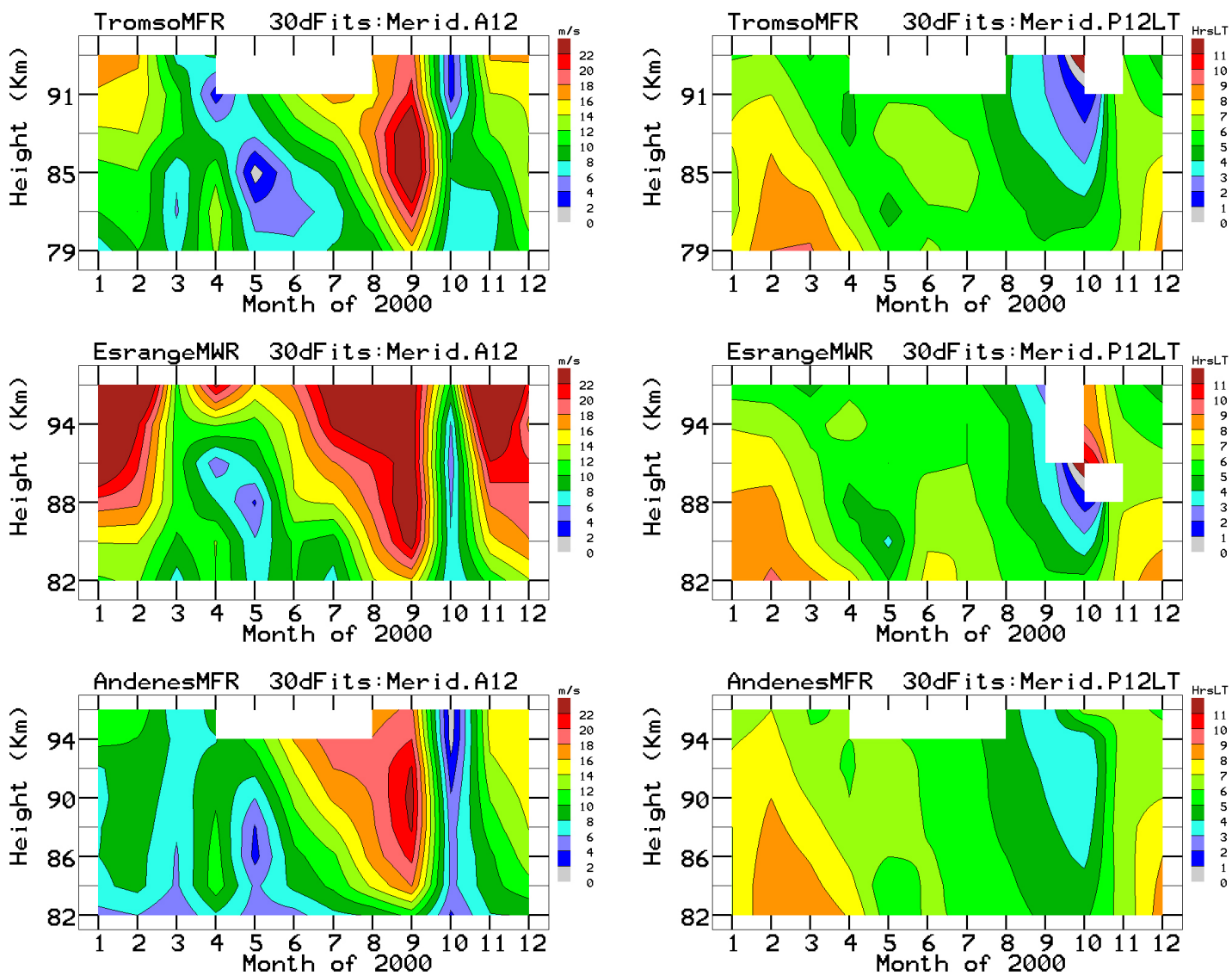

Fig. 5. Annual (2000) contours of the NS (meridional) component of the semi-diurnal tidal amplitudes (A12) and phases (P12LT; local solar times), as functions of height versus time: plots for Troms $\varnothing$, Esrange and Andenes are shown. The times are for the maximum tidal wind in the northward direction. Troms $\emptyset$ data are again shown for a height interval lower by $3 \mathrm{~km}$.

The Troms $\varnothing$ winds are modestly larger than Andenes (5\% median) and there is a seasonal change (Troms $\varnothing$ values are larger/smaller in winter/summer). Ratios for the EsrangeAndenes and Esrange-Troms $\varnothing$ pairs show the Esrange winds to be generally relatively larger than those for the two MFRs. As expected, the variance ratios at $88 \mathrm{~km}$ for EsrangeTroms $\varnothing$ are very similar to the values obtained from Fig. 3 . The surprising result is that the ratios for both comparisons with Esrange in Table 1 vary with month (smaller in summer than in winter) and with height (increasing with height usually). Median values (MWR/MFR) are 1.57 at $97 \mathrm{~km}$ and 1.1 at $85 \mathrm{~km}$. We have been unable to find a reason for these results.

\section{Mean Winds and Tides}

The annual contours of the EW (zonal) and NS (meridional) components of the mean winds, as functions of height versus time, are shown in Fig. 4. The height co-ordinates are different at Andenes due to the 2-km data-sampling. Also, we show Troms $\varnothing$ data from $79-94 \mathrm{~km}$ (original height calibration) for reasons of gaining colour/contour similarities with the other MLTs; if the 3-km height correction of Sect. 3 were then applied, the height range of the data would be the same for the three radars.

The zonal mean contours are then very similar in position and strength, except for the strong summer eastward cell above $90 \mathrm{~km}$ at Esrange. These are the altitudes that cannot be reached by the MF radar pulses without significant groupretardation or total reflection (Sect. 2). The heights of reversal of the EW flow are near $90 \mathrm{~km}$ at all MLT radars; Andenes $(92 \mathrm{~km})$, Troms $\varnothing(90+3=93 \mathrm{~km})$, Esrange $(89 \mathrm{~km})$. The slightly lower height for Esrange is consistent with the expected latitudinal trend. The structure/colours of the meridional (NS) contours are also very similar; the speeds are much lower than for the EW and so contours may change, dependent upon small differences in the wind vectors across the S-Triangle. In particular, in summer, the southward flow at Esrange is stronger for longer duration over more altitudes; and this is also true for heights below $90 \mathrm{~km}$, where the EW winds are very similar in magnitude to the other locations.

The contours of Fig. 4 do show larger variability of shape and position than do similar contour plots from the $50^{\circ} \mathrm{N}$ Canadian Triangle (not shown). This may be a regional effect, as the $70^{\circ} \mathrm{N}$ Triangle is in mountainous country relatively near to the ocean. Possible physical processes are discussed in the Conclusion. 


\section{GSWM2000}

\section{NS}
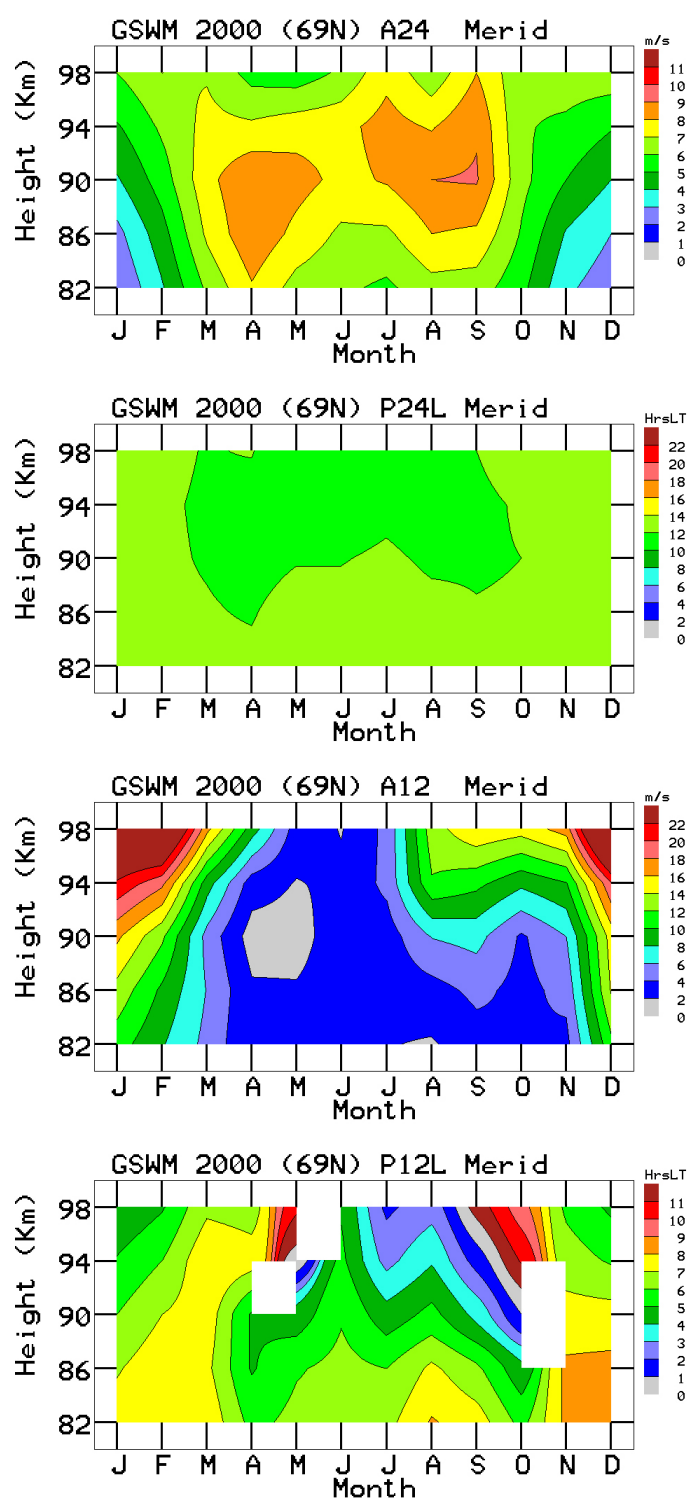

EW
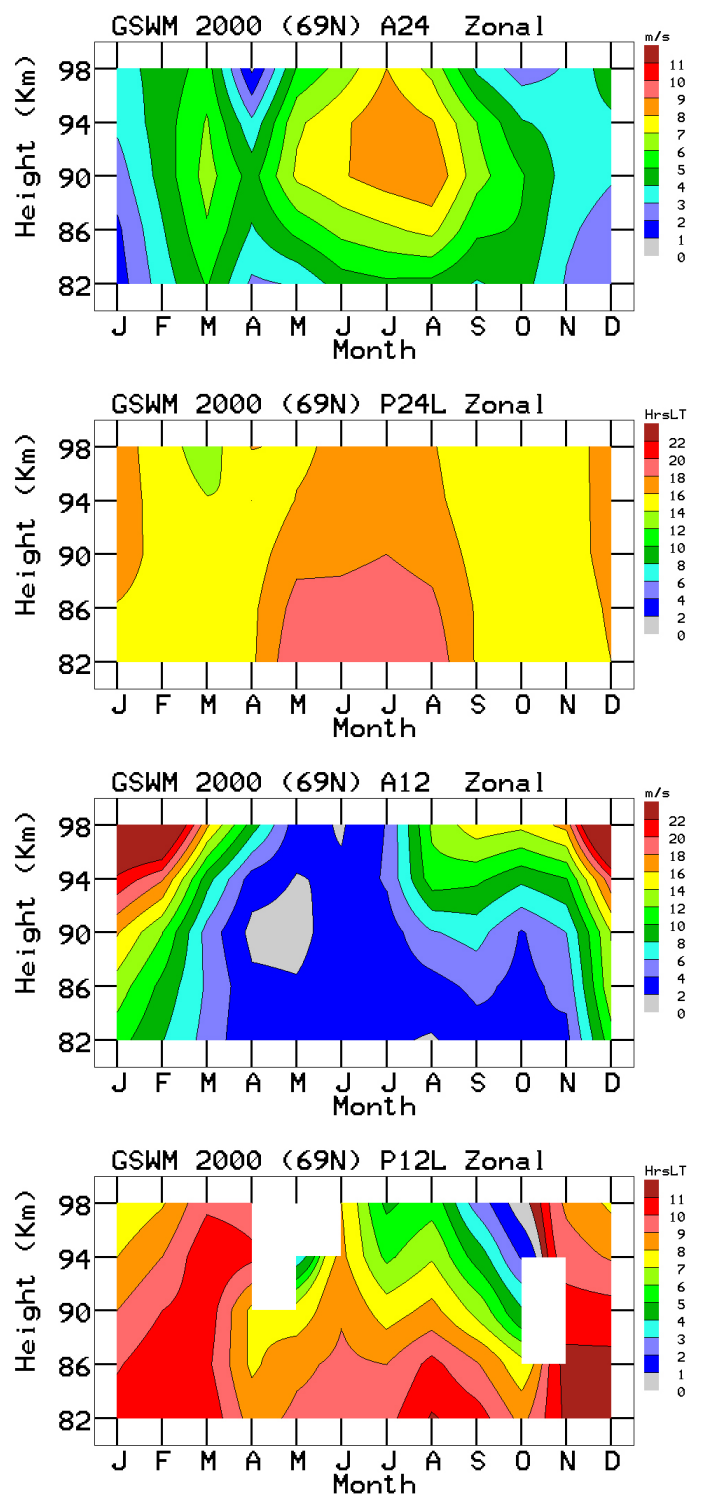

Fig. 6. GSWM-2000 (Global Scale Wave Model, year 2000 version): annual contour plots of the NS (meridional) and EW (zonal) components of the diurnal and semidiurnal tidal amplitudes (A24, A12) and phases (P24LT, P12LT; local solar times), as functions of height versus time, for the latitude $\left(69^{\circ} \mathrm{N}\right)$ nearest to the radars of the Scandanavian Triangle are shown. The times are for the maximum tidal wind in the northward and eastward directions.

The annual contours of the amplitudes and phases of the semi diurnal (12-h) tide are provided in Fig. 5: the meridional (NS) component is chosen, as the zonal portrays the same features but with the phases being closely in quadrature, as expected. The phases are appropriate to the local (solar) times at each radar location. Contours for amplitudes and phases are generally similar to those shown for the first time at $70^{\circ} \mathrm{N}$ (Troms $\varnothing$ ) by Manson and Meek (1991b). Tidal contours from Esrange have also been shown for the first six months of 2000 by Mitchell et al. (2002), and those essentially agree with the plots shown here. We focus first upon the strong similarities between the tidal oscillations observed by the three MLT radars: there are clear transitions in phases and phase-gradients between winter (wavelengths $\lambda \sim 50 \mathrm{~km}$ ) and early summer $(\lambda>100 \mathrm{~km})$; there are dominant late summer-autumn amplitude features, beginning at higher altitudes in June and maximizing near $90 \mathrm{~km}$ in September; there are very modest changes in phase during the development of 

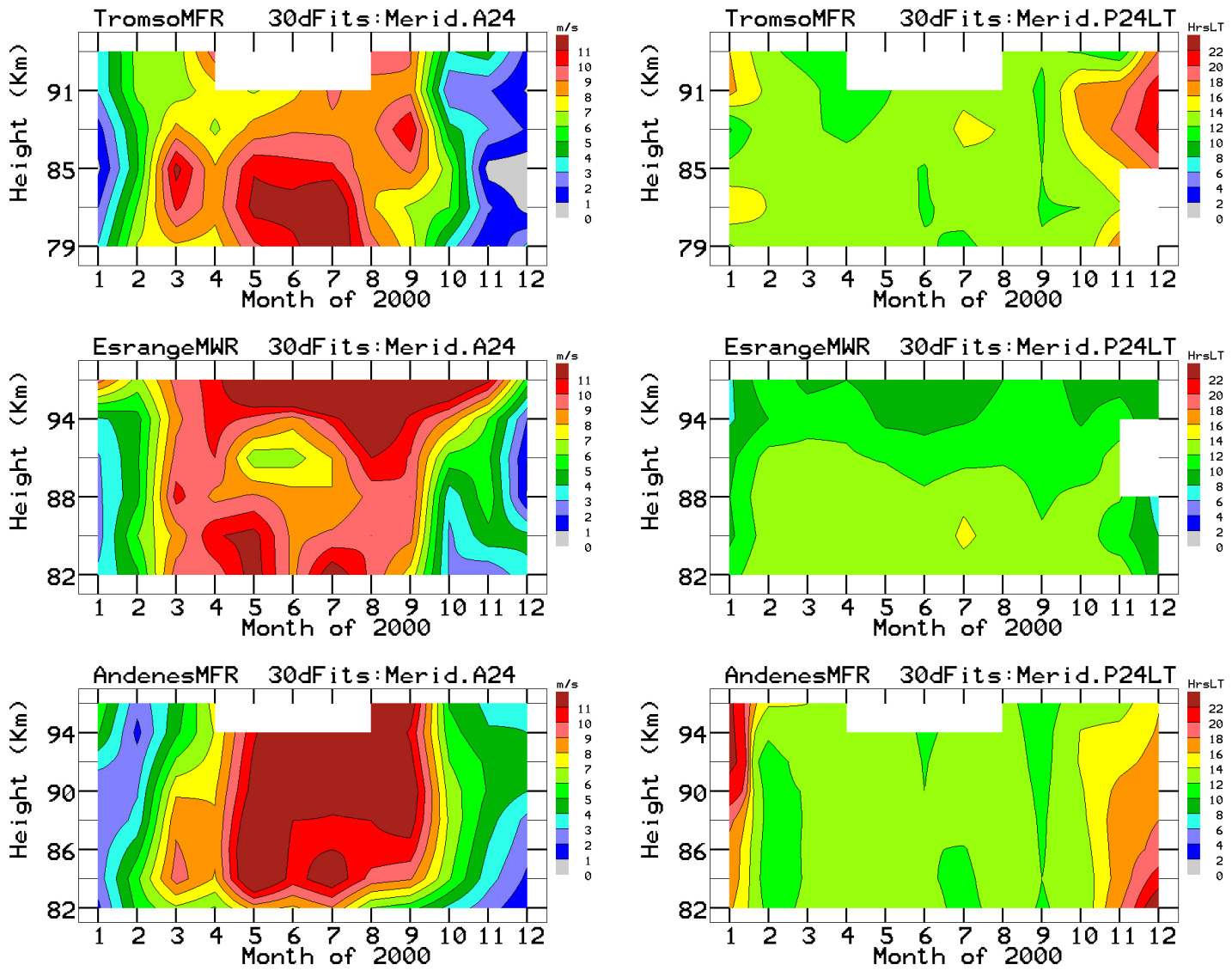

Fig. 7a. Annual (2000) contours for the (a) NS (meridional) and (b) EW (zonal) components of the diurnal tidal amplitudes (A24) and phases (P24LT; local solar times), as functions of height versus time: plots for Troms $\varnothing$ (3 km height interval difference), Esrange and Andenes are shown. The times are for the maximum tidal wind in the northward and eastward disrections.

this feature; and the largest temporal changes in phase occur in October, between the autumn amplitude maxima and the developing maxima of the winter solstice.

There are also interesting differences between the 12-h tidal amplitudes (Fig. 5) for the three locations. First, the similarities between Andenes and Troms $\varnothing$ features are enhanced by the $+3 \mathrm{~km}$ adjustment in height gates for Troms $\varnothing$, as discussed earlier. Secondly, the amplitudes of the tide at Esrange are clearly greater above $88 \mathrm{~km}$ than at the other locations, consistent with the "scatter plots" of Fig. 3 and Table 1 of Sect. 3. This affects the structure/colours of the autumn maxima and especially the winter solstice maxima (Esrange/Troms $\varnothing$, amplitudes $\cong 1.4$ ). However, there are also differences between MFR locations, as although their autumn features are very similar and strong $(>20 \mathrm{~m} / \mathrm{s})$, the Andenes amplitudes in winter (January) are much weaker than at Troms $\varnothing$ (Troms $\varnothing /$ Andenes $\cong 1.5)$. (These differences exist in the EW component also). The changes in contours associated with variations of analysis at any site, for example, by using un-weighted hourly values (Sect. 2), are smaller than the differences noted between the three MLT radars. It is not possible to determine whether the changes between Troms $\varnothing$ and Andenes are related to MFR antenna-system differences, but the experience with the Canadian-Triangle suggests that this is not a significant issue as far as the tides are concerned. It should also be noted that the latitudinal tidal studies involving Troms $\varnothing$ (Manson et al., 1999b, 2002b) have shown significant inter-annual variability at Troms $\varnothing$, as well as differences between EW and NS components in some years.

We include a figure using the GSWM-2000 (Global Scale Wave Model, year 2000 version; Hagan et al., 1999; Manson et al., 2002b), for comparison purposes (Fig. 6). The winter phase-contours for the 12-h tide, along with their vertical gradients, agree well with those observed at the three sites for both NS and EW components; and the observed strong phase gradients of October are shown by GSWM2000. However, the modelled vertical phase-gradients from April-September differ substantially, with unobserved wavelengths of $\sim 30 \mathrm{~km}$. The amplitude contours of the model show a strong winter maximum, similar in absolute terms to Esrange, but there is only a modest maximum at the upper levels centred on September. Otherwise, the amplitudes are much weaker (factors of near 2) than observed by the MLT radars. Possible reasons for the differences between modelled and observed tides are discussed in the Conclusions. It is certainly valuable to conduct comparisons of such contour plots at specific locations, as this is the most demanding test of the model; tidal differences are not as evident in the lati- 

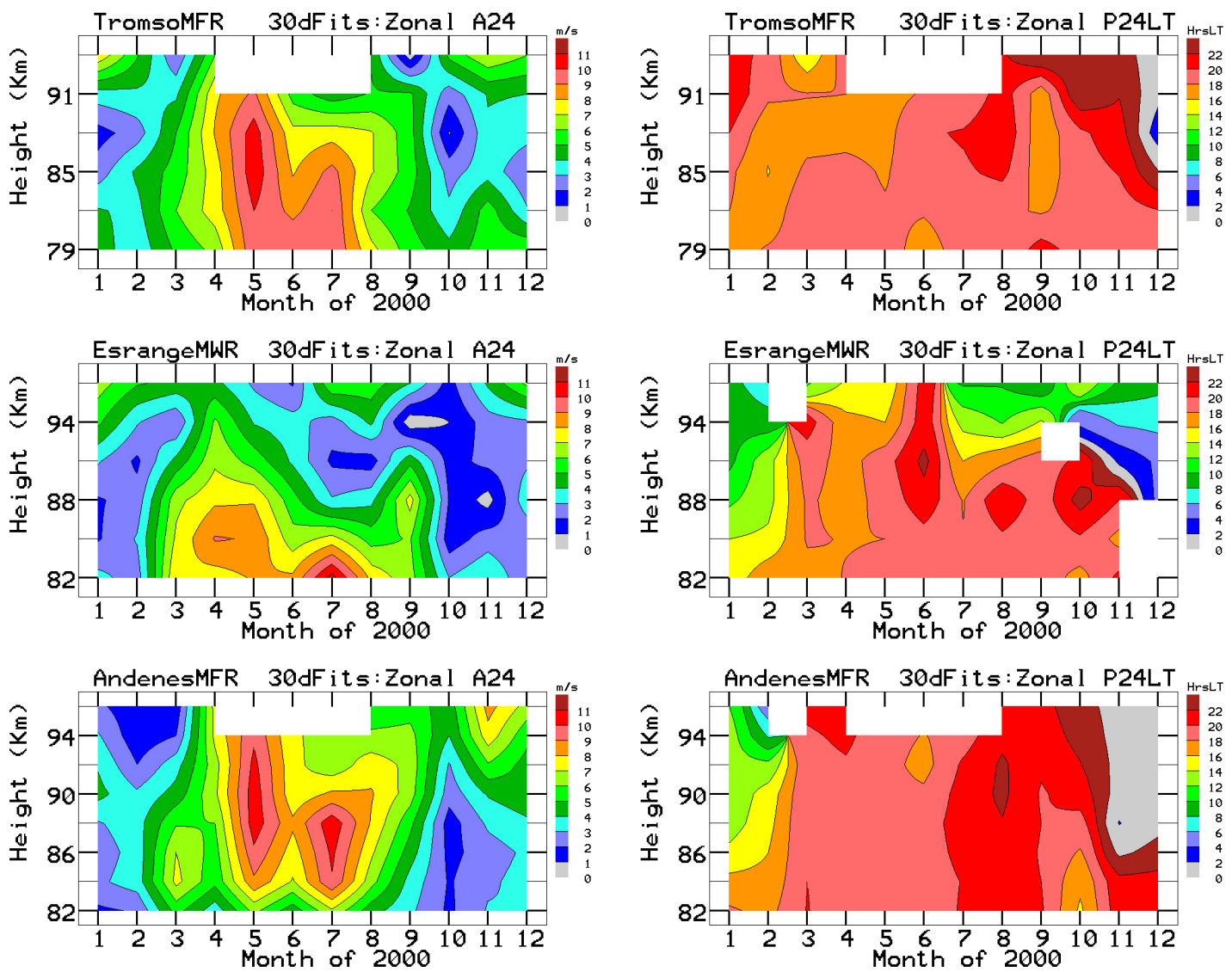

Fig. 7b. See Fig. 7a.

tudinal plots of various types which have been used in other studies, for example, Manson et al. 2002b.

A brief comment on the differences between the 12-h tidal characteristics at $70^{\circ} \mathrm{N}$ and mid-latitudes $\left(40-52^{\circ} \mathrm{N}\right)$ is appropriate (Manson et al., 2003a). The amplitude contours of the latter are also dominated by the winter and late summerautumn peaks, although these latter are restricted to August and September. Amplitudes in these peaks are somewhat larger (factors of 1-2) than at $70^{\circ} \mathrm{N}$, as also shown by Manson et al. (2002b). The phase structures and gradients are quite similar at high and middle latitudes, suggesting similar mode composition. Finally, the amplitude-phase contours for the $50^{\circ} \mathrm{N}$ Canadian-Triangle (not shown) do demonstrate slightly less variability with height and time over $500 \mathrm{~km}$ than do, say, those of the Andenes-Troms $\varnothing$ MFR pair. This is also discussed in the Conclusions.

The annual contours for the amplitudes and phases of the diurnal (24-h) tide are provided in Figs. 7a, b: both of the components are shown, as although they portray similar broad seasonal features, there are significant differences within the summer-centred months. The amplitudes of this tide are approximately half those of the 12-h tide (note that the maximum contour level is $11 \mathrm{~m} / \mathrm{s}$ rather than $22 \mathrm{~m} / \mathrm{s}$ ). Contours for the amplitudes and phases are generally similar to those shown originally for Tromsø by Manson and Meek (1991b). We focus again first upon the strong simi- larities in EW and NS oscillations seen by the three MLT radars: the amplitudes are largest in a broad feature from March to September, for which the phases evidence generally small vertical gradients; and the vertical phase gradients are stronger in the winter months. It is not obvious that the $+3 \mathrm{~km}$ adjustment in the height-gates for Troms $\varnothing$ enhances the similarities between locations in this case, due to the greater variability in this tide.

Considering now the component differences for March until September, there are consistent decreases in amplitude with increasing height for the EW component (Fig. 7b), especially in mid to late summer, which contrasts with the NS component (Fig. 7a). The phase gradients are often larger and more irregular in the regions of small EW amplitude (Esrange and Tromsø). Such features may be due to small tidal signals. There are interesting differences between the contour plots for the three locations, and for each of the components. Again, the changes in contours at any site, associated with variations in analysis, for example, using unweighted hourly values (Sect. 2), are smaller than those between the MLT radars. Considering the NS component contours (Fig. 7a), the amplitude structures in the summer-centred months differ at each location, so there is no consistency in the amplitude ratios between locations; and the phases at Troms $\varnothing$ and Andenes are very similar in the non-winter months throughout the MLT region, while Es- 

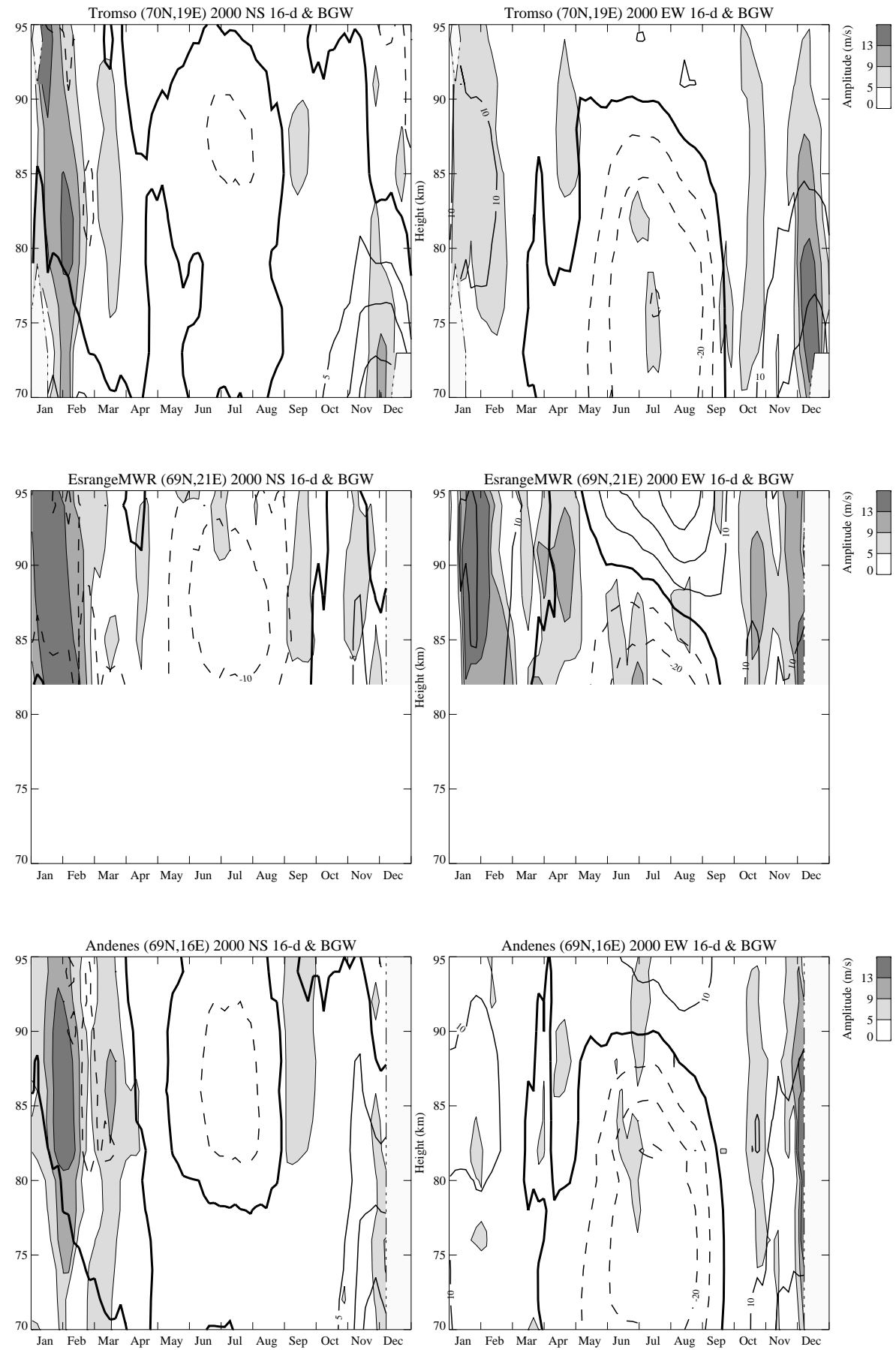

Fig. 8. Annual contours of wave amplitudes for the meridional and zonal (NS, EW) components of the 16-d PW, as functions of height versus time: plots for Troms $\emptyset$, Esrange and Andenes are shown. The background-mean winds (BGW) are shown by the use of continuous (eastward, northward) or dashed lines (westward, southward). Analysis details are provided in Sect. 2.

range shows a small but consistent vertical gradient above $90 \mathrm{~km}$. Finally, for the EW component (Fig. 7b), there is general similarity of the rather complex amplitude contours, although the amplitudes at Esrange in July-November are clearly the smallest. Regarding phases, there are months when any one pair of radars evidence very similar contour structures and gradients for example, phases at Esrange and Andenes in January-February.
Comparing with GSWM-2000 (Fig. 6), the model also has summer maxima, but the height-time structures of the contours differ significantly from the observations. However, the peak-amplitudes $(\sim 10 \mathrm{~m} / \mathrm{s})$ are similar, and the NS contours do show enhanced values over an extended interval from spring to autumn, which is similar to the observations. Regarding phases, the absolute values for the EW component (14-20 h) are similar to observations, but the phase structures 
and gradients differ; and for the NS component the phase values $(10-14 \mathrm{~h})$ and their gradients are very similar in the nonwinter months. The vertical phase gradients of both components do not show the observed tendency for larger values in the winter. It must be reiterated that GSWM is a 2-D model, and the non-migrating tidal modes so evident from global satellite analysis (Manson et al., 2002a, 2004b) will typically lead to local observations, such as those for the S-Triangle, being different from the model.

Commenting now on the differences in 24-h tidal characteristics at $70^{\circ} \mathrm{N}$ and mid-latitudes $\left(40-52^{\circ} \mathrm{N}\right)$, the amplitude contours of the latter are dominated by late summer and autumn, and late winter-spring peaks; and the absolute values decrease strongly from Platteville to Saskatoon and then to the S-Triangle (Manson et al., 2002b, 2003a). The phase structures also differ, with the high latitude dominance of the evanescent mode $(\mathrm{S}(1,-1))$ being modified at mid-latitudes by the propagating mode (e.g., $\mathrm{S}(1,1))$. This is especially evident in winter, when relatively short wavelength structures $(\sim 50 \mathrm{~km})$ may occur. Finally, the amplitude-phase contours for the $50^{\circ} \mathrm{N}$ Canadian Triangle (not shown) demonstrate slightly less variability with height and time over $500 \mathrm{~km}$ than do those of the Scandinavian-Triangle; but for both locations the variability of the 24-h tidal oscillations is significantly greater than that of the 12-h tidal oscillations.

\section{Planetary waves}

\subsection{6-d PW}

The annual contours of wave amplitudes for the EW and NS components, as functions of height versus time, over the Scandanavian-Triangle are shown in Fig. 8. The backgroundmean winds (BGW) for the 48-day window (Sect. 2.2) are also shown. The relative amplitudes within the MLT region and across the S-Triangle are consistent with the spectra of Fig. 2: the NS amplitudes often dominate the EW; the wave activity (amplitudes above $5 \mathrm{~m} / \mathrm{s}$ ) is largest in winter-centred months; and the wave activity is restricted to mesopause heights $(\sim 80 \mathrm{~km})$ in summer.

Considering Fig. 8 in more detail, the 16-d PW activity (NS) in winter extends throughout the MLT (70-95 km). The greater range of data obtained from the MFRs in the mesosphere $(70-82 \mathrm{~km}$ ) is also very evident (the tidal figures of the previous section could also have shown some data at these heights, but the emphasis there was upon comparative climatologies). There are two substantial bursts of activity centred especially on January-February and to a weaker extent in December at all three stations; the Jan.-Feb. event is strong in the NS component at the three radars, while there is activity at Esrange and Troms $\varnothing$ but not at Andenes for the EW component. The amplitudes are largest at Esrange, but this is likely to be mainly due to the speed bias discussed in Sect. 2 . Otherwise some of the variations of wave activity in the first "grey scale" of 5-9 m/s, especially in the summer, are pos- sibly associated with noise, as amplitudes of circa $5 \mathrm{~m} / \mathrm{s}$ are usually at the $90 \%$ significance level (Luo et al., 2000.)

The recent studies of this wave (Luo et al., 2002a, b) noted its spatial and temporal intermittency, with bursts of activity occurring at different times at the MFR locations: Troms $\varnothing\left(70^{\circ} \mathrm{N}, 19^{\circ} \mathrm{E}\right)$, Saskatoon $\left(52^{\circ} \mathrm{N}, 107^{\circ} \mathrm{W}\right)$, London $\left(43^{\circ} \mathrm{N}, 81^{\circ} \mathrm{W}\right)$, Hawaii $\left(22^{\circ} \mathrm{N}, 160^{\circ} \mathrm{E}\right)$, Christmas Island $\left(2^{\circ} \mathrm{N}, 157^{\circ} \mathrm{E}\right)$. Also, results from UARS-HRDI (Luo et al., 2002b), which were based upon hemispheric wave mode $(m=1)$ fits, showed strong latitudinal restrictions in the bursts of activity. Theoretically, this wave is expected to propagate from the lower atmosphere and through the eastward flow of the winter hemisphere, with the possibility of summer mesopause activity due to propagation from the winter hemisphere. The results from the 2-D Global Scale Wave Model (GSWM) in Luo et al., (2000, 2002b) were generally consistent with this simple scenario, but also demonstrated strong sensitivity to the background winds in the model, for example, strong winter winds can lead to the so-called "critical velocity" of Charney and Drazin (1961) being exceeded, the refractive index becoming smaller, and wave propagation being minimized. Also, Hagan et al. (1993) very nicely address the issue of intermittency for planetary waves. They note that variations of the relative magnitudes of the summer and winter "jets" on time scales of weeks could account for the intermittency; and that the resonant period of the wave is sensitive to these changes in the "jets". Such effects would be associated with the propagation of both 16- and 2-d PWs, and lead to their observed interannual variability.

The latitudinal plots of Luo et al. (2002b) showed that above $82 \mathrm{~km}$ the observed EW amplitudes for 1993-5 were comparable at $52^{\circ} \mathrm{N}$ (Saskatoon) and $70^{\circ} \mathrm{N}$ (Troms $\varnothing$ ), and that the observed and modelled (GSWM) NS amplitudes were comparable or greater than the EW amplitudes at $70^{\circ} \mathrm{N}$. Our present results are consistent with these earlier studies.

\subsection{2-d PW}

The annual contours of wave amplitudes for the 2-d PW at the three MLT radars are shown in Fig. 9; the same format as Fig. 8 has been used. Despite the considerable number of studies of this wave type over the last two decades (for example, Meek et al., 1996; Thayaparan et al., 1997), contour plots of this type have not been widely used. Emphasis has been placed upon the bursts of activity during summer months (July-August in the N.H.) at mesopause heights. In that context we note the modest summer mesopause activity (amplitudes 6-8 $\mathrm{m} / \mathrm{s}$ ) in both EW and NS components at all three MLT radars; the strongest burst is at the end of July in the NS component, when amplitudes exceed $10 \mathrm{~m} / \mathrm{s}$. However, the general level of activity at $70^{\circ} \mathrm{N}$ is much lower than at $40-52^{\circ} \mathrm{N}$ (Manson et al., 2003a, 2004a), where bursts occur from June to August.

Of greater note is the modest but consistent winter activity that can be seen throughout the MLT at all stations. Nozawa et al. (2003), using Troms $\varnothing$ MFR and EISCAT observations, have studied these winter waves in some detail. The winter 

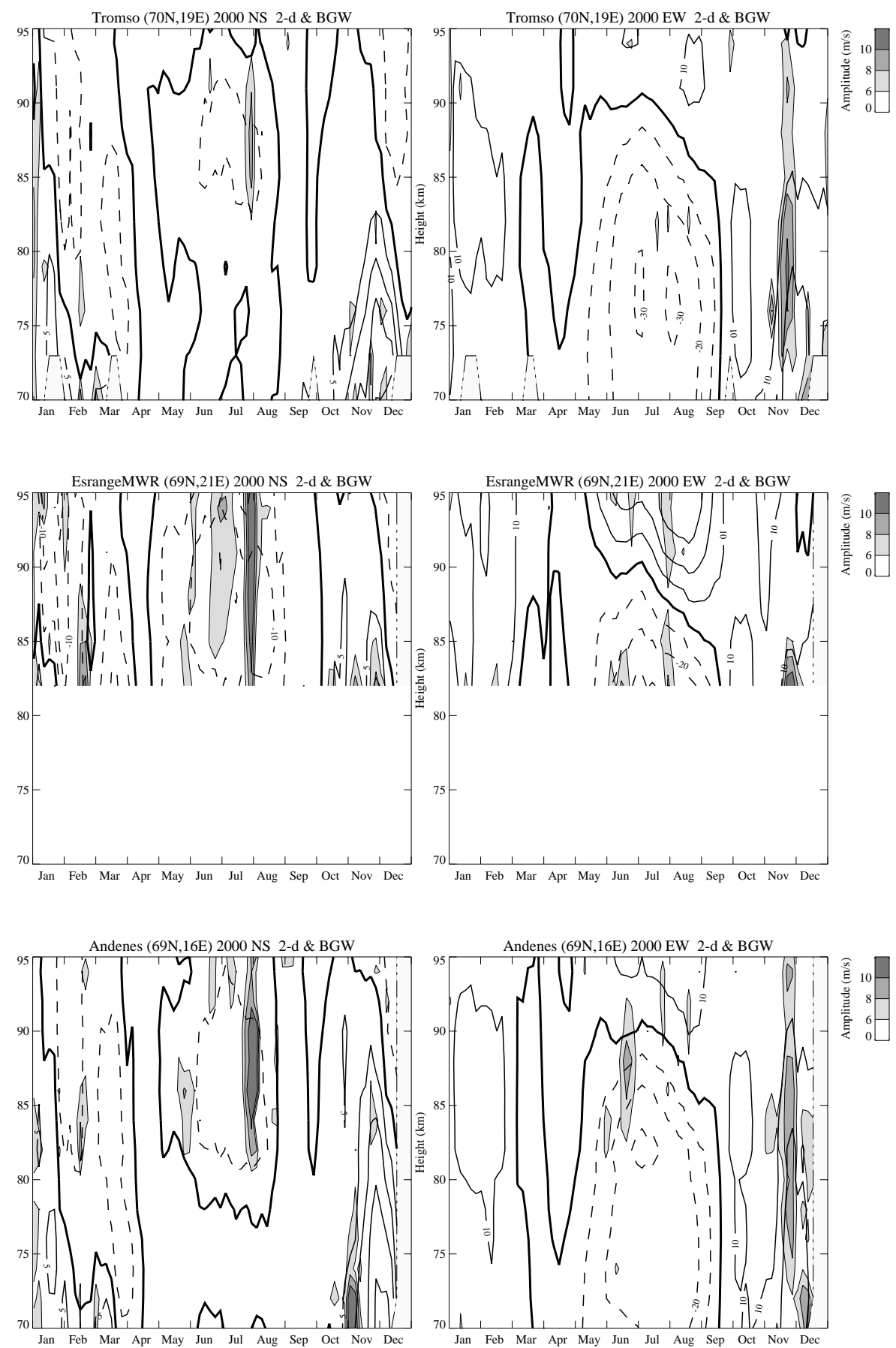

Fig. 9. Annual contours of wave amplitudes for the zonal and meridional (EW, NS) components of the 2-d PW, as functions of height versus time: plots for Troms $\varnothing$, Esrange and Andenes are shown. The background-mean winds are shown by the use of continuous (eastward, northward) or dashed (westward, southward) lines. Analysis details are provided in Sect. 2.

activity is also very clear and even stronger at $40-52^{\circ} \mathrm{N}$ (Manson et al., 2003a, 2004a), and the absence of an earlier study of the winter wave has to be a minor embarrassment to the community.

Theoretically, the behaviour of the 2-d PW is consistent with the discussion above on the 16-d PW. However, in contrast to the 16-d PW, the faster moving (wave numbers, $m=3$ or 4 are typical) 2 -d wave does not experience a critical level in the summer mesospheric westward flow, and achieves significant amplitudes (Hagan et al., 1993, Figs. 2, $4,6)$ at mesopause heights $(85-90 \mathrm{~km})$ and at middle to high latitudes. (Maximum responses are between the equator and $\pm 30^{\circ}$.) In winter the eastward flow leads to larger intrinsic phase speeds, and the so-called "critical velocity" (Charney 

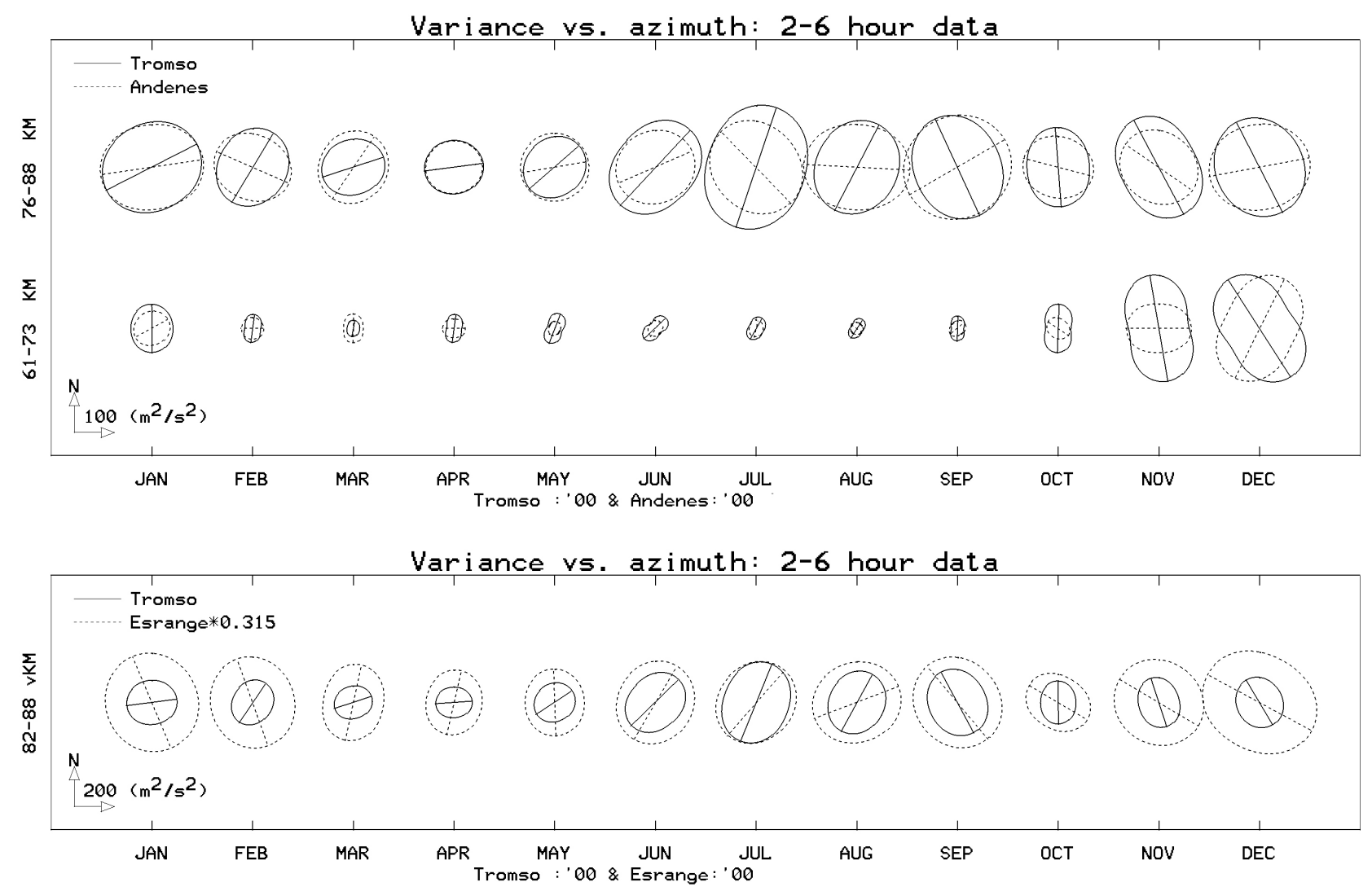

Fig. 10. Variances of the winds from the 2-6 hour band-pass filter, as a function of azimuth, for two height layers, from the three MLT radars of the Scandinavian-Triangle: scales for the intensities and the orientation are shown. The resulting "perturbation ovals" are shown in pairs for ease of comparison.

and Drazin, 1961; Luo, 2002c), that is a function of both phase speed and wave number, is smaller for the 2-d wave (than for the 16-d PW) and rather more easily exceeded. Hence, the amplitudes of this wave are expected to be smaller in winter, as Hagan et al. (1993) demonstrate. This modest solstitial difference in the GSWM's response has been overstated, however, by interpreters of this paper, as the results here (and at $40-52^{\circ} \mathrm{N}$, by the CUJO network, Manson et al., 2003a, 2004a) show substantial winter amplitudes.

\section{Gravity Waves}

As described in Sect. 2, a band-pass filter has been applied to the winds' time-sequences, to allow for an assessment of GW intensities and directional properties in the 2-6h band (Fig. 10). Earlier studies have involved these "perturbation ovals" (years 1993/4) in the Canadian prairies over the $500 \mathrm{~km}$ triangle (Manson et al., 1997), and from $2-70^{\circ} \mathrm{N}$ (Manson et al., 1999a). In that context there are no surprises in Fig. 10: the sizes of the ovals follow semi-annual oscillations (SAO) at 76-88/82-88 km, and annual oscillations at the $61-73 \mathrm{~km}$ layer. The orientations of the ovals at the upper layer are interesting; they are more zonal at Andenes, while at Esrange and Troms $\varnothing$ there are more months when the meridional direction is preferred. The amplitudes are quite similar across the S-Triangle, although except for the summer months the Esrange ovals are somewhat larger than at the other two locations. This, and the tendency for the Esrange ovals to be more meridionally orientated, could be associated with the distribution of meteor trails within the antenna beams. The large area involved with the distribution of these trails (Sect. 2, circa 500km) will also tend to increase the variance compared with the MFR systems (for example, Nakamura et al., 2002). Otherwise, the reasonable agreement between the Troms $\varnothing$ and Esrange ovals (compared with other radar comparisons we have done) is pleasing, given that an MWR has not been used for this analysis before.

It is useful to compare the spatial variations over the S-Triangle with those noted over the $500 \mathrm{~km}$ MFR CanadianTriangle. For the latter, very modest changes in perturbation oval size and orientation were noted between the purely east-west pair of Saskatoon and Sylvan Lake radars. The Troms $\varnothing$-Andenes MFR pair in Fig. 10 clearly demonstrates more directional variability. However, for the SaskatoonRobsart MFR pair, where Robsart is located $500 \mathrm{~km}$ southwest, strong directional changes (often as much as 90 degrees, and more zonal than meridional) were observed. Also, Robsart ovals were modestly larger. In that context the differences between the ovals of Troms $\varnothing$ and Esrange, two loca- 
tions that are really quite similarly spaced, are qualitatively similar to the Canadian pair.

Our earlier studies using 1993/4 data (Manson et al., 1999a) had shown that the GW intensities (ovals) were surprisingly large in the Troms $\emptyset$ area, comfortably exceeding the Saskatoon values. We have assessed the years 19982001 and while there were some very large summer months in 1998 and 1999, during 2000 and 2001 the Tromsø MFR ovals were generally smaller than those for Saskatoon. It is, therefore, clear that interannual variability is a significant factor with this GW characteristic. It is also clear that our earlier suggestion that the intensities are large across the entire northern Scandinavian region was based upon insufficient evidence. The mountainous nature of the region and its proximity to the ocean and to changing weather patterns are possible explanations for the large inter annual variability, and indeed the spatial variability (Troms $\varnothing$-Andenes), which has also just been noted.

The reasons for changes in oval characteristics, both in size and in orientation, are clearly complex, and involve both sources and propagation conditions. Assessment of ovals from GCMs is, therefore, useful and our study of CMAM (Manson et al., 2002c) included the 2-6h band. More work of this nature is called for.

We make only brief comments about the possibilities for other GW analyses. There was relevant discussion already in the Introduction regarding the results of such GW analyses for the $500 \mathrm{~km}$ Canadian Triangle. Given the smaller size of the S-Triangle there were grounds for cautious optimism that a larger number of GW would be resolved and characterized.

Time-sequences of daily values from the $2-6 \mathrm{~h}$ band-pass filter were prepared for each radar location and for three height layers: 82-85, 88-91, 94-97 km. For each layer there were 15-20 days over the full year when significant peaks of variance were noted at each of the three MLT radars. However, these peaks were noted to exist over two neighbouring height-layers on only six instances, and the peaks were common to the three layers in only one instance. This horizontal uniformity, along with limited vertical correlation, is very similar to the GW-related characteristics noted for the Canadian Triangle (Hall et al., 1995a, b). A hodograph analysis, similar to that used in the earlier studies, will, therefore, be applied to these data in the future.

\section{Conclusions}

The existence of the three MLT radars in the ScandinavianTriangle has provided a unique opportunity both to compare systems and to assess the variability of all the atmospheric wave types over distances of $125-270 \mathrm{~km}$. Correlation techniques provided an independent method of height calibration for the radars, and inferred that the Troms $\varnothing$ radar data required a $+3 \mathrm{~km}$ adjustment for best agreement of the tidal winds across the Triangle. That analysis also allowed for wind (mainly tidal) speed comparisons: the Troms $\emptyset$ values are modestly larger (5\%) than those at Andenes, a difference consistent with different versions of the FCA winds analysis and possible differences in antenna systems; and the Esrange values are larger than those at the MFR sites (median annual factors of 1.6 at $97 \mathrm{~km}, 1.1$ at $85 \mathrm{~km}$ ). The variation of ratio with season (smaller in summer) and with height $(82-97 \mathrm{~km}$ with $3 \mathrm{~km}$ sampling) is a new result, and likely holds clues as to the reasons for this effect.

Annual contour plots for the winds, and for tidal amplitudes and phases, throughout the MLT region show strong similarities between the three radars of the S-Triangle(125$270 \mathrm{~km}$ spacings). However, the variability of shape and position of the contours is modestly larger than for the larger $(500 \mathrm{~km})$ Canadian Triangle of MFRs. This may be due to the proximity of this mountainous region to the Atlantic Ocean, from whence weather systems and related GW interactions and momentum deposition may lead to MLT dynamical variability, for example, Manson et al., 2002a, c. In the first of these papers, the smallest scale of global tidal longitudinal variability was shown to be comparable to that of the S-Triangle; and in the second the role of GW associated with orography was shown to be important in a high resolution General Circulation Model. There have also been numbers of theoretical studies (for example, Walterscheid, 1981; Zhong et al., 1995; Eckermann and Marks, 1996) which have explored the mechanisms by which variability of the harmonics (12-24 h) of the wind can be caused by GW interactions with the background wind. Here we have demonstrated a significant variation of GW activity across the S-Triangle. Most recently, Riggin et al. (2003) have discussed and studied the variability of high-latitude tides, and demonstrated the importance of the background winds and temperatures in refracting the semi-diurnal tide; there will be a regional scale of variability associated with this process.

The semi-diurnal tide has a climatology very similar to that at middle-latitudes, for example, strong transitions between summer (long wavelength) and winter (short wavelengths), but the amplitudes at times of maxima, for example, autumn, are smaller by factors of 1-2. The GSWM shows useful agreements with the MLT radars, but its summer vertical phase-gradients are much larger and the autumn amplitude maximum is too weak. The contour plots for the diurnal tide (24-h) reveal that the amplitudes are about half the size of the 12-h tide; the amplitudes are largest in nonwinter months, when the wavelengths are very large; and the wavelengths are smaller in winter. The GSWM-2000 also has a summer maximum, and the peak amplitudes and absolute values of the phases near $85 \mathrm{~km}$ are very similar to those observed. However, the rather complex height-time structures of the observed contours, which show considerable agreement between the three S-Triangle radars, are not reproduced by the mode, i.e., there is no indication of the observed shorter winter wavelengths. There are also strong observed tidal differences with those at middle-latitudes (cf. Manson et al., 2002b, 2003a) where amplitudes are larger and maxima occur closer to the equinoxes, reflecting the more important role of the $\mathrm{S}(1,1)$ mode. The non-migrating tidal modes (e.g. Manson et al., 2002a, 2004b), will contribute signifi- 
cantly to the detailed differences between the GSWM-2000 and the tides over the S-Triangle.

These detailed assessments of the Arctic tides, using contour plots with observed and modelled data, are a very useful addition to latitudinal studies (for example, Manson et al., 2002b, c) which necessarily give less insight into the local and individual characteristics throughout the MLT region. Studies of tides remain one of the most important themes of middle atmosphere dynamics: their structure and characteristics at MLT heights depend upon forcing from global ozone and water vapour distributions in the lower atmosphere, middle atmosphere wind and temperature fields and gradients, gravity wave influences through eddy diffusion and momentum depositions, and other wave interactions, for example, Hagan, 1996; Riggin et al., 2003; Manson et al., 2002c, 2004b). Thus, successful global modelling of the tides would indicate profoundly substantial knowledge and understanding of the chemical, thermal and dynamical state of the middle atmosphere, including the MLT. In this regard, global ozone data of significantly improved seasonal, altitudinal, latitudinal and longitudinal distribution are becoming availabl, for example, Murtagh et al., 2002. Given the importance of ozone-forcing for both diurnal and semidiurnal tides (Hagan, 1996), the incorporation of these new data into tidal models, such as GSWM, and even Global Circulation Models through data assimilation, are likely to provide tides in better agreement with observations.

The climatologies of the high-latitude PW have been shown to differ significantly from those at middle-latitudes. For the 16-d PW, although the EW amplitudes during the maxima of winter activity are similar in magnitude to those for the lower latitudes, the NS components on occasion dominate the EW over the S-Triangle. Modest, but still statistically significant, differences between the contour plots for the three radars again indicate the spatial and temporal intermittency of the local wind oscillations associated with these global-scale PW structures (Luo et al., 2002a, b). This, again, may be associated with variations of $\mathrm{GW}$ activity across the S-Triangle. The 2-d PW activity across the Triangle is quite coherent, but the summer amplitudes and general activity throughout the year are, respectively, smaller and less than at middle latitudes. Winter activity ( $\mathrm{EW}>\mathrm{NS}$ amplitudes) is actually greater than in summer $(\mathrm{EW}<\mathrm{NS})$, a fact that is only now receiving proper attention, for example, Nozawa et al. (2003). The annual contour plots for the MLT region provided here put this seasonal activity of PW into even clearer context. This pattern of seasonal activity is also very clear at middle-latitudes (Manson et al., 2003a, b), which again is a surprise to those content with studying the summer manifestation of this "quasi-two day PW". Given the importance of interactions between PW and GW (Manson et al., 2003b; McLandress and McFarlane, 1993), and the role of PW in producing non-migrating tides (e.g. Hagan and Roble, 2001), improved understanding and modelling of PW activity at Arctic latitudes is very desirable.

In conclusion, the monthly presentation of $\mathrm{GW}$ variances in the form of "perturbation ovals", which provide ampli- tudes as functions of azimuthal directions, have illustrated that the seasonal trends of the variances are quite consistent across the S-Triangle (this is the first time that such analysis has been applied to the MWR data), and that annual and semiannual oscillations (solstitial minima) are strong. However, the GW variances and oval orientations do evidence considerable spatial and interannual variability, when compared with those of the Canadian Prairies. Hence, and due to the interactions of GW with tides and planetary waves, we suggest an important role for these waves in the overall dynamics of the Scandinavian Arctic.

Acknowledgements. The scientists gratefully acknowledge grants from their national agencies (NSERC in Canada). The first authors (Manson, Meek) also acknowledge support from the University of Saskatchewan, and the Institute of Space and Atmospheric Studies.

Topical Editor Ulf-Peter Hoppe thanks two referees for their help in evaluating this paper.

\section{References}

Bremer, J., Hoffmann, P., Manson, A. H., Meek, C. E., Ruster, R., and Singer, W.: PMSE observations at three different frequencies in northern Europe during the summer 1994, Ann. Geophysicae 14, 1317-1327, 1996.

Briggs, B. H.: The analysis of spaced sensor records by correlation techniques, Handbook for MAP, Vol. 13. SCOSTEP, University of Illinois, Urbana, 166- 186, 1984.

Charney, J.G. and Drazin, P.G.: Propagation of planetary-scale disturbances from lower into the upper atmosphere, J. Geophys. Res., 66, 83 -109, 1961.

Eckermann, S. D., and Marks, C. J.: An idealized ray model of gravity wave-tidal interactions; J. Geophys. Res. 101, 21195 $21212,1996$.

Gavrilov, N. M., Manson, A. H., and Meek, C. E.: Climatological monthly characteristics of middle atmosphere gravity waves (10-10h) during 1979-1993 at Saskatoon, Ann. Geophysicae 13, 285-295, 1995.

Hagan, M. E., Forbes, J. M., and Vial, F.: Numerical Investigation of the Propagation of the Quasi 2-Day Wave into the Lower Thermosphere, J. Geophys. Res., 98, 23,193-23, 205, 1993.

Hagan, M. E., Comparative effects of migrating solar sources on tidal signatures in the middle and upper atmosphere; J. Geophys. Res. 101, 21 213-21 222, 1996.

Hagan, M. E., Burrage, M. D., Forbes, J. M., Hackney, J., Randel, W. J. and Zhang, X.: GSWM-98: Results for migrating solar tides, J. Geophys. Res., 104, 6813-6827, 1999.

Hagan, M. E. and Roble, R. G.: Modeling diurnal tidal variability with the NCAR TIME-GCM, J. Geophys. Res. 106, 24869 $24882,2001$.

Hall, C. M.: The Ramfjordmoen MF radar $\left(69^{\circ} \mathrm{N}, 19^{\circ} \mathrm{E}\right)$ : application development 1990-2000, J. Atmos. Sol. Terr. Phys., 63, 171-179, 2001.

Hall, G. E., Namboothiri, S. P., Manson, A. H., and Meek, C .E.: Daily tidal, planetary wave, and gravity wave amplitudes over the Canadian Prairies, J. Atmos. Terr. Phys., 57, 1553-1567, 1995a.

Hall, G. E., Meek, C. E, and Manson, A. H.: Hodograph analysis of mesopause region winds observed by three MF radars in the Canadian Prairies, J. Geophys. Res., 100, 7411-7421, 1995 b. 
Hocking, W. K. and Thayaparan, T.: Simultaneous and co-located observations of winds and tides by $\mathrm{MF}$ and meteor radars over

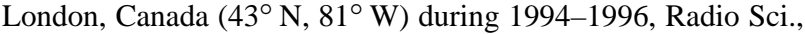
833-865, 1997.

Hocking, W. K., Fuller, B., and Vandepeer, B.: Real-time determination of meteor-related parameters utilizing modern digital technology, J. Atmos. Sol. Terr. Phys., 63, 155-169, 2001.

Kumar, P. and Foufoula-Georgiou, E.: Wavelet analysis for geophysical applications, Rev. Geophysics, 35, 385-412, 1997.

Luo, Y., Manson, A. H., Meek, C. E., Meyer, C. K., and Forbes, J. M.: The quasi 16-day oscillations in the mesosphere and lower thermosphere at Saskatoon $\left(52^{\circ} \mathrm{N}, 107^{\circ} \mathrm{W}\right), 1980-1996$, J. Geophys. Res., 105, 2125-2138, 2000.

Luo, Y., Manson, A. H., Meek, C. E., Igarashi, K., and Jacobi, Ch.: Extra long period (20-40 day) oscillations in the mesospheric and lower thermospheric winds: observations in Canada, Europe and Japan, and considerations of possible solar influences, J. Atmos. Sol. Terr. Phys., 63, 835-852, 2001.

Luo, Y., Manson, A. H., Meek, C. E., Thayaparan, T., MacDougall, J., and Hocking, W. K.: The 16-day wave in the mesosphere and lower thermosphere: simultaneous observations at Saskatoon $\left(52^{\circ} \mathrm{N}, 107^{\circ} \mathrm{W}\right)$ and London $\left(43^{\circ} \mathrm{N}, 81^{\circ} \mathrm{W}\right)$, Canada, $\mathrm{J}$ Atmos. Sol. Terr. Phys., 64, 1287-1307, 2002a.

Luo, Y., Manson, A. H., Meek, C. E., Meyer, C. K., Burrage, M. D., Fritts, D. C., Hall, C. M., Hocking, W. K., MacDougall, J., Riggin, D. M., and Vincent, R. A.: The 16-day planetary waves: multi-MF radar observations from the arctic to equator and comparisons with the HRDI measurements and the GSWM modeling results, Ann. Geophysicae, 20, 691-709, 2002b.

Luo, Y:: Influences of planetary waves upon the dynamics of the mesosphere and lower thermosphere, Ph. D. Thesis, 2002c.

Manson, A. H. and Meek, C. E.: Gravity Wave Propagation Characteristics $(60-120 \mathrm{~km})$ as determined by the saskatoon MF radar (Gravnet) System: $1983-85$ at $52^{\circ} \mathrm{N}, 107^{\circ} \mathrm{W}$, J. Atmos. Sci., 45, 932-946, 1988.

Manson, A. H., and Meek, C. E.: The effects of Geomagnetic Disturbances and Atmospheric Tides Upon Middle Atmosphere winds and MF radar scatter at Saskatoon $\left(52^{\circ} \mathrm{N}, 107^{\circ} \mathrm{W}, 61^{\circ}\right.$ Geomagnetic), J. Geophys. Res., 96, 915-926, 1991a.

Manson, A. H., and Meek, C. E.: Climatologies of mean winds and tides observed by medium frequency radars at Troms $\varnothing\left(70^{\circ} \mathrm{N}\right)$ and Saskatoon $\left(52^{\circ} \mathrm{N}\right)$ during 1987-1989, Canadian Journal of Physics, 69, 966-975, 1991b.

Manson, A. H., Meek, C. E., Brekke, A., and Moen, J.: Mesosphere and lower thermosphere $(80-120 \mathrm{~km})$ winds and tides from near Troms $\varnothing\left(70^{\circ} \mathrm{N}, 19^{\circ} \mathrm{E}\right)$ : comparisons between radars (MF, EISCAT, VHF) and rockets, J. Atmos. Terr. Phys., 54, 927-950, 1992

Manson, A. H., Yi, F., Hall, C., and Meek, C. E.: Comparisons between instantaneous wind measurements made at Saskatoon $\left(52^{\circ} \mathrm{N}, 107^{\circ} \mathrm{W}\right)$ using the co-located medium frequency radars and Fabry-Perot interferometer instruments: climatologies (1988-1992) and case studies, J. Geophys. Res., 101, 29553 29563, 1996.

Manson, A. H., Meek, C. E., and Zhan, Q.: Gravity wave spectra and direction statistics for the mesosphere as observed by MF radars in the Canadian Prairies $\left(49^{\circ} \mathrm{N}-52^{\circ} \mathrm{N}\right)$ and at Troms $\varnothing$ $\left(69^{\circ}\right.$ N), J. Atmos. Sol. Terr. Phys., 59, 993-1009, 1997.

Manson, A. H., Meek, C. E., Hall, C., Hocking, W .K., MacDougall, J., Franke, S., Igarashi, K., Riggin, D., Fritts, D. C., and Vincent, R. A.: Gravity wave spectra, directions and wave interactions: Global MLT-MFR network, Earth Planets Space,
51, 543-562, 1999a.

Manson, A. H., Meek, C., Hagan, M., Hall, C., Hocking, W., MacDougall, J., Franke, S., Riggin, D., Fritts, D., Vincent, R., and Burrage, M.: Seasonal variations of the semi-diurnal and diurnal tides in the MLT: multi-year MF radar observations from 2 to $70^{\circ} \mathrm{N}$, and the GSWM tidal model, J. Atmos. Sol. Terr. Phys., 61, 809-828, 1999b.

Manson, A.H., Luo, Y., and Meek, C.: Global distributions of diurnal and semi-diurnal tides: Observations from HRDI-UARS of the MLT region, Ann. Geophysicae, 20, 1877-1890, 2002a.

Manson, A. H., Meek, C., Hagan, M., Koshyk, J., Franke, S., Fritts, D., Hall, C., Hocking, W., Igarashi, K., MacDougall, J., Riggin, D., and Vincent, R.: Seasonal Variations of the semi-diurnal and diurnal tides in the MLT: Multi-year MF radar observations from $2-70^{\circ} \mathrm{N}$, modelled tides (GSWM, CMAM), Ann. Geophysicae, 20, 661-677, 2002b.

Manson, A. H., Meek, C. E., Koshyk, J., Franke, S., Fritts, D., Riggin, D., Hall, C., Hocking, W., MacDougall, J., Igarashi, K., and Vincent, R. A.: Gravity wave activity and dynamical effects in the middle atmosphere $(60-90 \mathrm{~km})$ : Observations from an MF/MLT radar network, and results from the canadian middle atmosphere model (CMAM), J. Atmos. Sol. Terr. Phys, 64, 65-90, 2002c.

Manson, A. H., Meek, C. E., Avery, S. K., and Thorsen, D.: Ionospheric and dynamical characteristics of the MLT region over Platteville $\left(40^{\circ} \mathrm{N}, 105^{\circ} \mathrm{W}\right)$ and comparisons with the region over Saskatoon $\left(52^{\circ} \mathrm{N}, 107^{\circ} \mathrm{W}\right)$, J. Geophys. Res., 108, (D13), 4398 , doi:10.1029/2002 jd002835, 2003a.

Manson, A. H., Meek, C. E., Luo, Y., Hocking, W. K., MacDougall, J., Riggin, D., Fritts, D. C., and Vincent, R. A.: Modulation of gravity waves by planetary waves $(2$ and $16 \mathrm{~d})$ : Observations with the north american-pacific MLT-MFR Rradar network, J. Atmos. Sol. Terr. Phys., 65, 85-104, 2003b.

Manson, A. H., Meek, C. E., Avery, S. K., Thorsen, D., Hocking, W., MacDougall, J. W., Igarshi, K., Nmamboothiri, S. P., and Murayama, Y.: Longitudinal and Latitudinal Variations in Dynamic Characteristics of the MLT (70-95 km): A study involving the CUJO network, Ann. Geophysicae, 347-365, 2004a.

Manson, A. H., Meek, C., Hagan, M., Zhang, X., and Luo, Y. Global distributions of diurnal and semi-diurnal tides: Observations from HRDI-UARS of the MLT region and comparisons with GSWM-02 (migrating, non-migrating components), Ann Geophysicae, in press 2004b.

McLandress C. and McFarlane N. A.: Interactions between orographic gravity-wave drag and forced stationary planetary-waves in the winter northernhemisphere middle atmosphere, J. Atmos. Sci., 50, 1966-1990, 1993

Meek, C. E.: An efficient method for analyzing ionospheric drifts data. J. Atmos. Terr. Phys., 42, 835-839, 1980.

Meek, C. E., Reid, I. M., and Manson, A. H.: Comparison of medium frequency pulsed radar interferometer and correlation analysis winds (1), handbook for MAP, Vol. 20, SCOSTEP, University of Illinois, Urbana, 293-298, 1986.

Meek, C. E., Manson, A. H., Franke, S. J., Singer, W., Hoffmann, P., Clark, R. R., Tsuda, T., Nakamura, T., Tsutsumi, M., Hagan, M., Fritts, D. C., Isler, J., and Portnyagin, Y.I .: Global study of northern hemisphere quasi 2-day wave events in recent summers near $90 \mathrm{~km}$ altitude, J. Atmos. Terr. Phys., 58, 1401-1411, 1996.

Meek, C. E., Manson, A. H., Burrage, M. D., Garbe, G., and Cogger, L. L.: Comparisons between canadian prairie MF radars, FPI (green and $\mathrm{OH}$ lines) and UARS HRDI systems, Ann. Geophysicae, 15, 1099-1110, 1997. 
Mitchell, N. J., Pancheva, D., Middleton, H. R., and Hagan, M. E.: mean winds and tides in the arctic mesosphere and lower thermosphere. J. Geophys. Res., 107, A1, 10.1029/2001 JA900127, 2002.

Murtagh, D., Frisk, U., Merino, F., Ridal, M., Jonsson, A., Stegman, J., Witt, G., Eriksson, P, Jimenez, C., Megie G., de la Noc. J., Ricaud, P., Baron, P., Pardo, J. R., Hauchcorne, A., Llewellyn, E. J., Degenstein, D. A., Gattinger, R. L, Lloyd, N. D., Evans, W. F. J, McDade, I. C., Haley, C. S., Sioris, C., von Savigny, C., Solheim, B. H., McConnell, J. C., Strong, K., Richardson, E. H., Leppelmeier, G. W., Kyrola, E., Auvinen, H., and Oikarinen, L.: An overview of the odin atmospheric mission, Canadian Journal of Physics, 80, 309-319, 2002.

Nakamura, T., Morita, S., Tsuda, T., Fukunishi, H., and Yamada, Y.: Horizontal structure of wind velocity field around the mesopause region derived from meteor radar observations, J. Atmos. Sol. Terr. Phys., 64, 947-958, 2002.

Namboothiri, S. P., Manson, A. H., and Meek, C. E.: E-region real heights and their implications for MF radar-derived wind and tidal climatologies, Radio Sci. 28, 187-202, 1993.

Nozawa, S., Imaida, S., Brekke, A., Hall, C. M., Manson, A., Meek, C., Oyama, S. Dobashi, K., and Fujii, R.: The quasi 2-day wave observed in the polar mesosphere, J.Geophys. Res., 108, D2, 10.1029/2002JD002440, 2003.
Riggin, D. M., Meyer, C. K., Fritts, D. C., Jarvis, M. J., Murayama, Y., Singer. W., Vincent, R. A. and Murphy, D. J.: MF radar observations of seasonal variability of semi-diurnal motions in the mesosphere at high northern and southern latitudes, J. Atmos. Sol. Terr. Phys., 65, 483-493, 2003.

Thayaparan, T., Hocking, W .K., and MacDougall, J.: Middle atmospheric winds and tides over London, Canada $\left(43^{\circ} \mathrm{N}, 81^{\circ} \mathrm{W}\right)$ during 1992-1993, Radio Sci., 30, 1293-1309, 1995.

Thayaparan, T., Hocking, W. K., MacDougall, J., Manson, A. H., and Meek, C. E.: Simultaneous observations of the 2-day wave at London $\left(43^{\circ} \mathrm{N}, 81^{\circ} \mathrm{W}\right)$ and Saskatoon $\left(52^{\circ} \mathrm{N}, 107^{\circ} \mathrm{W}\right)$ near $91 \mathrm{~km}$ altitude during the two years of 1993 and 1994, Ann. Geophysicae, 15, 1324-1339, 1997.

Walterscheid, R. L.: Inertio-gravity wave induced accelerations of mean flow having an imposed periodic component: Implications for tidal observations in the meteor region, J. Geophys. Res., 86, 9698-9706, 1981.

Zhong, L., Sonmor, L. J., Manson, A. H., and Meek C. E.: The influence of time-dependent wind on gravity-wave propagation in the middle atmosphere, Ann. Geophysicae 13, 375-394, 1995.

Zhong, L., Manson, A. H., Sonmor, L. J., and Meek, C. E.: Gravity wave exclusion circles in background flows modulated by the semidiurnal tide, Ann. Geophysicae, 14, 557-565, 1996. 